


\title{
IN-PLANE DYNAMIC EXCITATION OF AAC MASONRY WALLS PATCHED WITH FRP: DYNAMIC TESTING AND ANALYSIS
}

\author{
DVIR ELMALICH AND Oded RABINOVITCH
}

\begin{abstract}
The paper studies the dynamic behavior of autoclave aerated concrete (AAC) masonry walls externally strengthened with composite materials and subjected to in-plane dynamic loads. The study combines experimental, analytical and numerical methodologies, presents the results of two types of dynamic tests, and uses them for comparison with a finite element approach that is based on specially tailored high-order finite elements. The first dynamic test focuses on the natural frequencies and vibration modes of the patched wall. The second set of tests focuses on the dynamic response of the wall to in-plane base excitation. The analysis uses the specially tailored finite elements, combines them with conventional elements, and compares the results with the experiments. The discussion supports the validation of the model and throws light on a range of phenomena that characterize the dynamic behavior of the strengthened wall. These phenomena range from the global in-plane to out-of-plane coupling to the localized effects at the strengthened layer level.
\end{abstract}

\section{Introduction}

The structural upgrade of existing masonry walls is a challenge that is often faced by the structural engineering community. The presence of masonry walls in the structural assembly can affect the dynamic response of the entire structure, especially in cases where the dynamic excitation is in the wall's plane. In these cases, the strengthening of the existing walls can modify their own dynamic response and can also modify the response of the entire structure. However, in order to use such walls as a part of the lateral load resisting system, their strengthening is often required. The use of externally bonded fiber reinforced plastic (FRP) has gained widespread acceptance as a modern way to address this need.

In order to use FRP bonding in dynamic upgrade applications, the dynamic behavior of the strengthened wall in general and particularly the dynamic interaction between the existing wall and the external strengthening layers, have to be characterized. These aspects are relevant to the strengthening of the wall to resist out-of-plane dynamic loads (e.g. [Hamed and Rabinovitch 2008; Rabinovitch and Madah $2012 \mathrm{a} ; 2012 \mathrm{~b}]$ ) and they become even more important when the wall is strengthened to resist in-plane dynamic loads and to contribute to the general dynamic upgrade of the structure. The strengthening task requires a sound experimental basis and adequate analytical and numerical tools. The experimental basis is essential for characterizing the structural response and for providing experimental benchmarks for the assessment, examination, and validation of analytical and numerical tools. The analytical and numerical tools are then essential for widening the characterization of the structure and for addressing aspects that cannot be detected experimentally.

Keywords: dynamic analysis, dynamic tests, masonry walls, composite materials, finite element method, validation. 
The experimental studies that focus on the in-plane loading and response of the FRP strengthened walls are divided into three main groups. The distinction between the groups is based on the type of the loading (static, cyclic, dynamic) and on the scale of the tested sample. The first group aims to assess the shear behavior of masonry panels and includes small scale panels or block triplets subjected to quasistatic loading. For example, Ehsani et al. [1997] and Suriya Prakash and Alagusundaramoorthy [2008] examined masonry triplets strengthened with FRP sheets and pointed at the effect of the orientation of the fibers on the shear resistance. Hamid et al. [2005] examined small scale FRP strengthened masonry panels made of hollow concrete blocks and subjected to different load directions. The results were used for the derivation of strength parameters for simplified models but they also revealed the impact of the direction of the load on the nature of the response. This response varies from splitting of the blocks when the load is perpendicular to the masonry course to shearing of the bed joints when the load is parallel to the masonry course. These observations raise questions regarding the response in the case of realistic, sign reversing, and orientation changing dynamic loads.

The group of experimental works that focus on small scale specimens also reveals some of the local phenomena that govern the FRP strengthened masonry wall. Among these, delamination and rupture of the FRP layer [Valluzzi et al. 2002; Hamid et al. 2005; Ehsani et al. 1997] and delamination due to buckling [Suriya Prakash and Alagusundaramoorthy 2008] are reported. In that sense, the experiments that focused on small scale specimens provide insight into such physical phenomena. The small scale tests also provide a measure of the structural properties of the strengthened panel. However, these experiments do not address some of the critical aspects of the response of the wall and particularly those related to the dynamic effects (cyclic loading, sign reversing loading, inertial effects, velocity-governed effect etc.).

The second group of experimental studies examines larger FRP strengthened panels that are subjected to cyclic loading. This class of experiments focuses on the global behavior of the strengthened wall to the in-plane load and mainly on the impact of the configuration of the strengthening system on the global response. Within this group, a distinction is made between infill walls and load bearing walls. Haroun and Ghoneam [1997] and Saatcioglu et al. [2005] studied infill walls combined with concrete frames under cyclic loading. Almusallam and Al-Salloum [2007] studied the effect of strengthening with strips made of FRP fabrics. The alignment of the fibers of the strengthening layers in the first and third of these papers was along the bed joint, while in the second the fibers were oriented along the diagonal. The comparison between the two indicates that the configuration of the composite materials directly affect the response, which varies from a pseudoductile behavior with a modest contribution to the ultimate strength in the case of horizontal and vertical fibers, to stiffer, stronger, and less ductile behavior in the case of the diagonal fibers. This trend is also reflected by the experimental results reported in [Altin et al. 2008].

The general focus on the global response and on the impact of global parameters such as type, size, and orientation of the strengthening system is also found in experimental studies on FRP strengthened load bearing walls. Stratford et al. [2004] studied the behavior of such walls under a cyclic loading but with loading, unloading, and reloading in one direction only. The role of the sign reversal of the loads and its impact on the response of the wall were not examined. Foster et al. [2005] studied the behavior of FRP strengthened load bearing walls with opening and examined configurations that combine vertical and diagonal strengthened strips. These experiments confirm that the FRP system can postpone the structural degradation observed in the unstrengthened walls. However, they do not directly reflect the response to a fully dynamic load. 
The third group of experimental works includes direct dynamic tests of FRP strengthened walls. This class of experiments is essential for providing insight into the dynamic response and for setting experimental benchmarks for analytical and numerical models. In this class, the inertial forces and the damping effects dictate the response of the wall. The coupling effects that evolve due to the combination of realistic boundary conditions, direct dynamic loading, and inevitable imperfections are also taken into account. For example, Al-Chaar and Hasan [2002] examined the behavior of two parallel walls, one was unstrengthened and the other one was strengthened with FRP sheets. The two dynamically tested walls were made of concrete masonry units (CMU) and they supported a concrete slab. The walls were dynamically excited using a shake table in three directions. The response of these walls reveals some phenomena that characterize walls made of CMU and soft mortar. In particular, they reveal web splitting and cracking along the joints. ElGawady et al. [2002; 2003; 2005] examined the dynamic behavior of FRP strengthened walls made of clay bricks. Also here, the unstrengthened walls accumulated damage mainly along mortar joints. The FRP strengthening improved the resistance to cracking and therefore improved the dynamic lateral resistance of the walls. Turek et al. [2007] examined the dynamic response of masonry walls made of high strength concrete blocks. The results of this experimental study further strengthen the observation that the response is strongly affected by the strength ratio dictated by the high strength masonry units and the low strength mortar joints. With the strength ratio examined, and regardless of the configuration of the FRP, the cracking pattern tends to follow the weak mortar joints.

The above survey designates the direct dynamic testing as the most appropriate methodology for studying the dynamic response of the FRP strengthened wall and for providing benchmark results for the assessment and validation of analytical or numerical models. The direct dynamic tests surveyed above contribute to this effort and gain insight into the dynamics of the strengthened wall. However, in order to provide a sound basis for comparison with advanced analytical and numerical models, including ones that take the interfacial interaction between the existing and the bonded layers into account (e.g. [Elmalich and Rabinovitch 2012a]) a more refined class of experimental results is needed. Specifically, results that can be used for comparing the natural frequencies, the mode shapes, the damping mechanisms, and the elastic deformation fields in the dynamically loaded wall and results that can reflect on the interaction between the dynamically loaded wall and the externally bonded FRP layers are needed.

Another aspect of the dynamic behavior of FRP strengthened masonry walls is associated with the range of masonry materials involved. In historic masonry buildings, heavy solid masonry units and weak mortars (if any) are usually found. In other cases, relatively heavy bricks, solid concrete blocks, or hollow concrete blocks are used as the construction material. The experimental efforts discussed above and particularly the direct dynamic tests have focused on such materials (see, for example, [Al-Chaar and Hasan 2002; ElGawady et al. 2002; 2003; 2005; Turek et al. 2007]). In these cases, the combination of relatively stiff and strong blocks with weak joints dictates a cracking pattern that is limited to the joints.

Opposed to the classical heavy block and soft joint masonry, many modern masonry infill walls and, in some cases, even load bearing masonry walls are built using solid autoclave aerated concrete (AAC) blocks. The AAC is lighter than standard masonry materials and the mortar/adhesive that is used for the construction is often stronger and stiffer than the blocks themselves. As a result, the behavior of the wall is less heterogeneous and less orthotropic and the cracking is not limited to the mortar joints. In addition, the relatively low tensile and shear strengths of the AAC may negatively affect the bond of the externally bonded system and the ability of the interfaces to transfer shear and peeling stresses. 
The above observations about the nature of the AAC-FRP system and the potential ability to convert existing AAC walls into dynamic load resisting elements, draw the attention to the FRP strengthening of AAC walls to resist in-plane dynamic loads. In spite of that potential, the dynamic strengthening of AAC panels with FRP did not gain much attention in the literature. The number of works that addressed this application mainly focus on the strengthening to resist out-of-plane loads [Hamed and Rabinovitch 2010], strengthening of AAC lintels [Memari et al. 2010], and synergic sandwich panels made of CFRP and AAC and subjected to static [Uddin et al. 2006; 2007] and impact loads [Serrano-Perez et al. 2007]. Reports on the application of FRP patched AAC walls for the dynamic in-plane upgrade and reports on the direct dynamic testing of FRP strengthened AAC masonry walls under dynamic in-plane loads were not found.

The objective of this paper is to gain insight into the dynamic response of FRP strengthened AAC masonry walls to dynamic in-plane loads. The paper also aims to present dynamic experimental results that can be used for the assessment and validation of analytical and numerical models for the dynamic behavior of the strengthened wall. Finally, it aims to use these results for the examination of a high order specially tailored finite element modeling approach [Elmalich and Rabinovitch 2012a; 2012b; 2012c]. To achieve these goals, the paper combines experimental and analytical/numerical methodologies. The experimental program focuses on direct dynamic testing of FRP patched AAC wall panels. The dynamic testing includes free vibration response to impulsive loads and forced dynamic response to base excitations. The combination of the experimental results and the high order FE analysis and the comparison between them are then used for studying additional aspects of the dynamic behavior of the FRP strengthened wall.

\section{Experimental program}

2.1. Test specimens, geometry, and materials. The tested AAC masonry specimens are illustrated in Figure 1. The tested panels are $750 \mathrm{~mm}$ wide, $900 \mathrm{~mm}$ high, and $100 \mathrm{~mm}$ deep. Each specimen is constructed of 6 courses of 250/150/100 AAC blocks. The construction of the specimens uses standard techniques, including the use of a special mortar/adhesive for joining the masonry blocks together. The tested panels include an unstrengthened one and a strengthened one. Both sides of the strengthened panel are patched with externally bonded GFRP sheets saturated with epoxy resin. The material properties of the masonry units, the masonry mortar/adhesive, and the GFRP system are listed in Table 1. These values are based on the materials' manufacturers. Some of the elastic and mechanical properties of the

\begin{tabular}{|ccccc|}
\hline Material & $\begin{array}{c}\text { Elastic modulus } \\
{[\mathrm{GPa}]}\end{array}$ & $\begin{array}{c}\text { Shear modulus } \\
{[\mathrm{GPa}]}\end{array}$ & Poisson ratio & $\begin{array}{c}\text { Dry density } \\
{\left[\mathrm{kg} / \mathrm{m}^{3}\right]}\end{array}$ \\
AAC block & $1.550-1.780$ & $0.62-0712$ & 0.25 & $540-560^{*}$ \\
AAC adhesive/mortar & 10 & 3.84 & 0.25 & 1300 \\
GFRP sheet & $65(x, y$ directions $)$ & 3.25 & - & 2600 \\
Epoxy adhesive/resin & 3 & 1.15 & 0.3 & 1100 \\
\hline
\end{tabular}

${ }^{*}$ Measured value $=550 \mathrm{~kg} / \mathrm{m}^{3}$

Table 1. Material properties (reported by the manufacturers). 


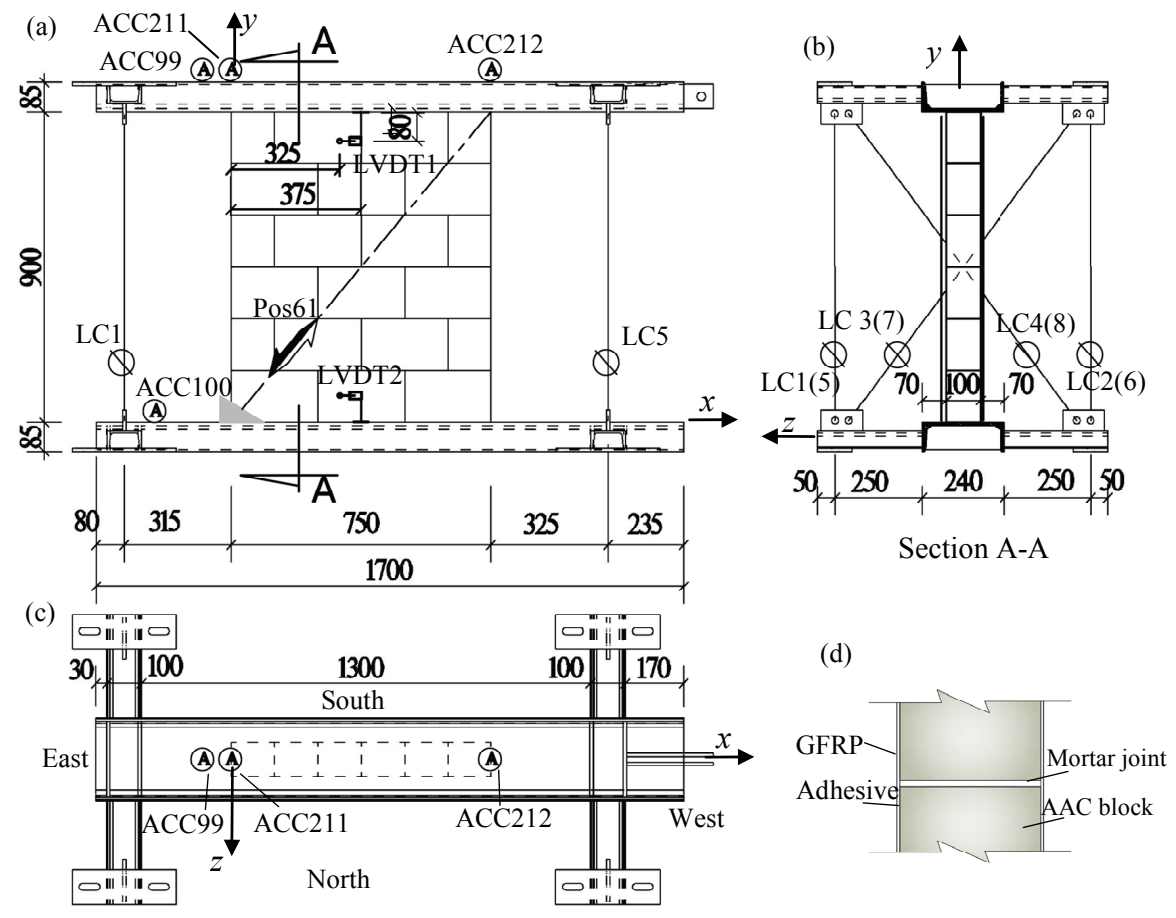

(e)

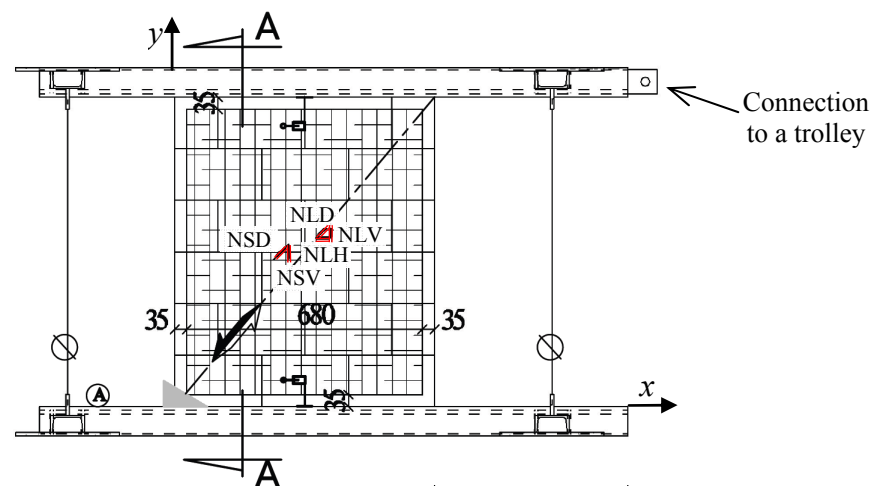

Figure 1. Experimental setup: (a) $x-y$ view; (b) cross section; (c) top view; (d) zoom on a cross section near the joint; (e) $x-y$ view of the FRP patched wall.

assembled AAC panel are further validated through a quasistatic diagonal compression test. Because this process is involved with data reduction through application of the FE model, it is reported later in this section, right after the presentation of the FE model.

2.2. Test setup. The test setup is also illustrated in Figure 1. A picture of the test setup and the tested specimens appears in Figure 2. For clarity of the discussion, a Cartesian coordinate system is "attached" to the specimen. In this system, $x$ designates the direction of the excitation (east-west), $y$ is the vertical coordinate, and $z$ is perpendicular to the wall's plane (north-south) see Figures 1 and 2. The panels 

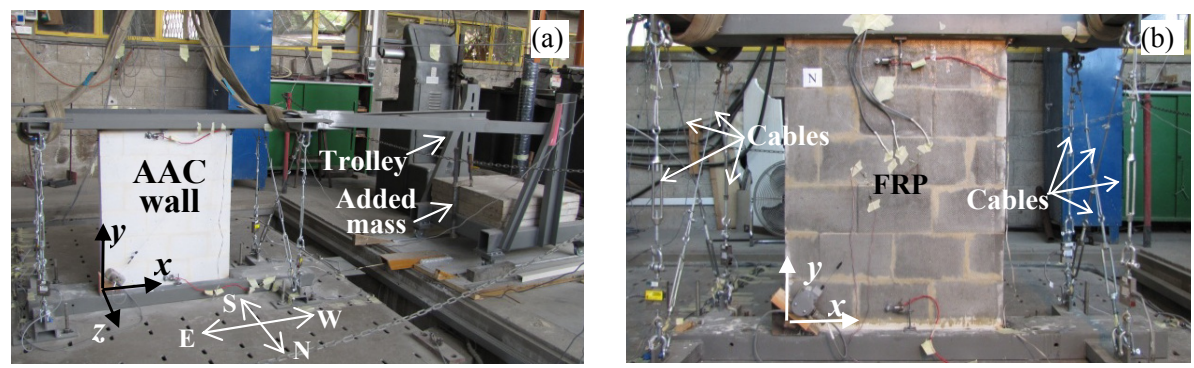

Figure 2. Experimental setup: (a) unstrengthened AAC panel; (b) FRP strengthened AAC panel.

are dynamically excited in the $x$ direction using a shake table. The masonry panels are built on top of a steel beam, which is rigidly mounted on the shake table. In order to apply vertical prestress to the wall, and in order to add mass at the top of the wall, an additional steel beam is mounted on top of the panel (see Figures 1 and 2). The mass of the top beam equals $60 \mathrm{~kg}$. The top and bottom beams are connected by two sets of cables. Each set includes two vertical cables and two diagonal cables. Each cable is pre-tensioned to $1 \mathrm{kN}$. The tensile forces in all cable are continuously monitored during the pre-tensioning stage and during the dynamic testing stage. The cable systems exert vertical compression on the panel (prestress) and they restrain the out-of-plane displacements (in the $z$ direction) of the top beam by forming two stiffened $y-z$ planes perpendicular to the wall's plane. However, due to the elastic deformability of the cables, the stiffened planes allow for some level of elastic movement of the upper beam in the $y$ and $z$ directions. This allows for the evolution of mode shapes that involve such movement of the top of the wall. The system of cables does not restrain the movement of the upper beam in the direction of the excitation $(x)$. As a result, the dynamic in-plane load is solely carried by the tested wall. In order to simulate the effect of added mass, which represents the contribution of an upper slab, in some of the experiments, the upper steel beam is connected to a trolley. The point where the trolley is connected to the upper beam is shown in Figure 1e. The trolley, which is shown in Figure $2 \mathrm{a}$, is free to move in the $x$ direction on leveled rails. The friction associated with its movement is not significant. The mass of the trolley equals $190 \mathrm{~kg}$ and it can carry added mass up to about $800 \mathrm{~kg}$. The added mass takes the form of concrete weights that are mounted on the chassis of the trolley (see Figure 2a). The trolley apparatus introduces the lateral effect of the added mass but it does not increase the vertical dead load on the shake-table.

2.3. Sensing and monitoring. The monitoring of the dynamic response uses 4 linear transducers (LVDT), 4 uni-axial (single-component) accelerometers, 1 position transducer, and 8 load cells. The location of the sensing devises is illustrated in Figure 1. The in-plane accelerations in the $x$ direction are measured at the level of the bottom beam by the accelerometer designated ACC100 and at the level of top beam by the accelerometer designated ACC99. The out-of-plane accelerations in the $z$ direction are measured using two additional accelerometers (ACC211 and ACC212). These sensors are mounted on the top beam at points that are located above the two upper corners of the wall. ACC211 is located above the east corner and ACC212 is located above the west one. The in-plane diagonal extension/contraction of the specimen is monitored using a position transducer (POS61). One end of this device is connected to 
the bottom beam at the lower east corner and the other end is connected to the top beam at the upper west corner. LVDT1 and LVDT2 are used for monitoring relative displacements in the $x$ direction. LVDT1 measures the relative displacement between a point located $80 \mathrm{~mm}$ below the upper steel beam and the upper beam itself. LVDT2 measures the relative displacement between a point located $80 \mathrm{~mm}$ above the bottom steel beam and the bottom beam itself. LVDT 3 monitors the movement of the shake table in the $x$ direction and LVDT4 monitors the movement of the trolley. Finally, all 8 cables are equipped with load cells (LC1-LC8) that dynamically monitor the level of the tensile forces in each cable.

The FRP strengthening system is monitored using two sets of strain gauges (SG) that are located on both faces of the wall near its center. The strain gages are marked with 3 letters. The first letter refers to the face of the wall ( $\mathrm{N}$ for north or $\mathrm{S}$ for south). The second letter refers to the length of the strain gage (S for $6 \mathrm{~mm}$ long strain gauges or $\mathrm{L}$ for $30 \mathrm{~mm}$ long strain gauges). The third letter refers to the direction of the strain gage ( $\mathrm{V}$ for vertical, $\mathrm{H}$ for horizontal, $\mathrm{D}$ for $45^{\circ}$ ).

The sampling rate of each sensor equals 1200 samples per second. In some tests, this value is reduced to 1000 samples per second. The specific sampling rate in each test is determined depending on the duration of the excitation and on the expected dominant frequencies.

2.4. Testing protocol. The panels are dynamically tested in two steps. First, the dynamic characteristics of the panels are examined under impulse induced free vibrations. Two methods have been used for the excitation of free vibration of the wall. The first method is based on moving the shake table at constant velocity and then a sudden breaking. The second method is based on hammering the top steel beam in the $x$ direction. Both scenarios yield an impulsive load in the $x$ direction.

The second step of the dynamic testing examines the response of the wall to a cyclic base excitation. In this step, the panels are subjected to a series of cyclic base movement signals. In the present paper, the focus is on excitation signals that are characterized by frequencies of $6 \mathrm{~Hz}$ and $4 \mathrm{~Hz}$ and on the response of the patched wall.

\section{High order FE modeling and analysis}

3.1. High order finite element. The numerical analysis of the FRP patched wall uses the specially tailored FE approach developed in [Elmalich and Rabinovitch 2012a; 2012b]. For completeness and clarity, the main modeling approach and the main modeling assumptions that are used in the derivation of the specially tailored FE are briefly outlined next. Then, the numerical model that implements the specially tailored element in the FE analysis of the entire test setup is outlined. Finally, the assessment of the mechanical properties to be used in the numerical model is discussed.

The specially tailored multilayered FE is presented in Figure 3. The element combines five layers that include the two FRP layers, the two adhesive layers, and the wall. The latter is assumed linear elastic, orthotropic, and geometrically linear. The wall layer is modeled using the first order shear deformation plate theory. Due to the small thickness of the mortar joints used in the AAC masonry assembly and due to the relatively high strength and high modulus of the AAC mortar/adhesive (compared with the AAC blocks), the mechanical properties of the masonry units and the joints are homogenized and the panel is modeled using the equivalent properties.

The FRP layers are assumed geometrically and physically linear, elastic, and symmetrically stacked. These layers are independently modeled using the lamination theory and the first order shear deformation 

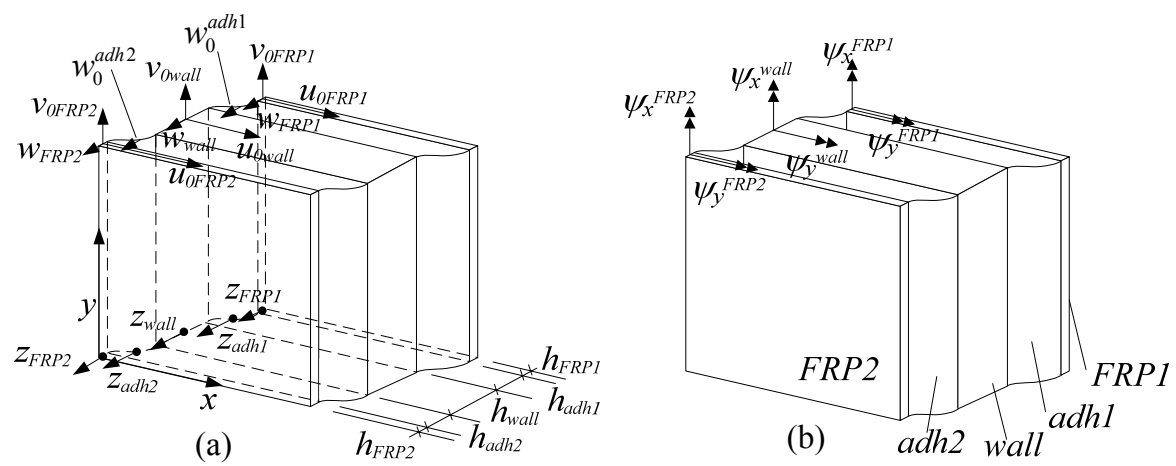

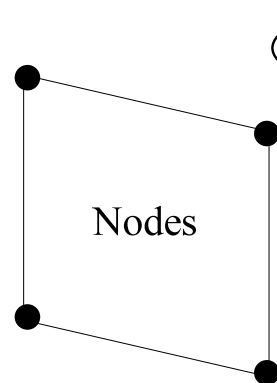

(c)

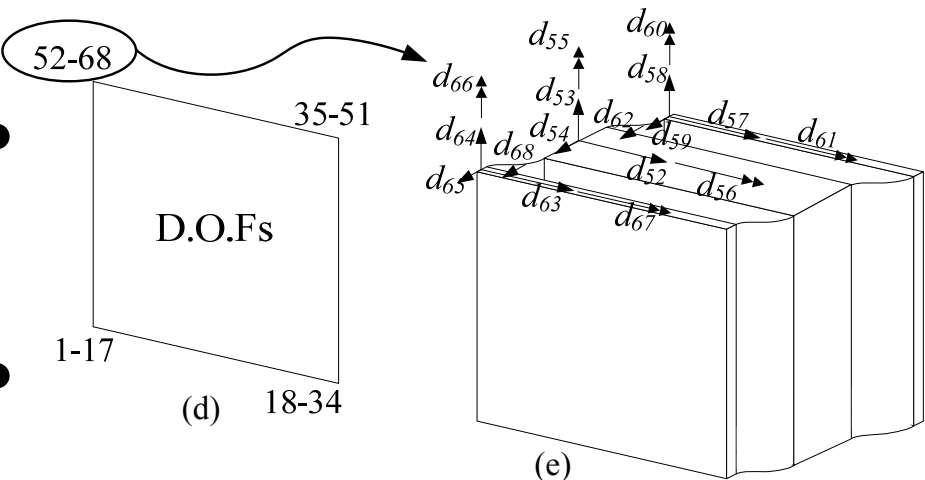

Figure 3. Notation and sign convention for the specially tailored high order element: (a) geometry, coordinate systems, and displacements; (b) rotations; (c) FE nodes; (d) FE degrees of freedom; (e) degrees of freedom in node 4.

plate theory. The adhesive layers are modeled as 3D elastic media. They are assumed physically and geometrically linear. The in-plane normal and in-plane shear rigidities of the adhesive layer are neglected compared with the rigidities of the adjacent components. For all components, the kinematic assumptions used for the dynamic analysis follow the ones used for the static case (see [Elmalich and Rabinovitch $2012 \mathrm{a}$; 2012b] for more details). The various layers are joined together by imposing the conditions of compatible in-plane and out-of-plane displacement at the interfaces. Therefore, it is assumed that all interfaces of the adhesive layers are fully bonded and that they can transfer shear and out-of-plane normal stresses. Finally, the effect of damping is introduced by means of a mass (external) and stiffness (viscous) proportional Rayleigh damping model.

The specially tailored finite element includes 4 nodes and 17 degrees of freedom (DOFs) per node [Elmalich and Rabinovitch 2012a]. The elemental nodes, the DOFs, and the corresponding displacements and rotations are shown in Figure 3. The first 5 DOFs correspond to the nodal displacements of the wall layer $\left(u_{0 \text { wall }}, v_{0 \text { wall }}, w_{\text {wall }}\right)$ in the $x, y$, and $z$ directions, respectively, and to the rotations $\left(\psi_{x}^{\text {wall }}, \psi_{y}^{\text {wall }}\right)$ of the wall's cross sections about the $x$ and $y$ axes, respectively. The following 10 nodal DOFs correspond to the displacements and rotations of the first FRP layer: $u_{0 \mathrm{FRP} 1}(x, y, t), v_{0 \mathrm{FRP} 1}(x, y, t), w_{\mathrm{FRP} 1}(x, y, t)$, $\psi_{x}^{\mathrm{FRP} 1}(x, y, t), \psi_{y}^{\mathrm{FRP} 1}(x, y, t)$ and to those of the second FRP layer: $u_{0 \mathrm{FRP} 2}(x, y, t), v_{0 \mathrm{FRP} 2}(x, y, t)$, 
$w_{\mathrm{FRP} 2}(x, y, t), \psi_{x}^{\mathrm{FRP} 2}(x, y, t), \psi_{y}^{\mathrm{FRP} 2}(x, y, t)$. The last two nodal DOFs correspond to the out-of-plane displacement at the middle of the adhesive layers: $w_{0}^{\mathrm{adh} 1}(x, y, t), w_{0}^{\mathrm{adh} 2}(x, y, t)$.

The displacements fields in the layered element take the following form [Elmalich and Rabinovitch 2012a]:

$$
\left\{\begin{array}{c}
u_{i}(x, y, z, t) \\
v_{i}(x, y, z, t) \\
w_{i}(x, y, z, t)
\end{array}\right\}=\left\{\begin{array}{c}
u_{0 i}(x, y, t) \\
v_{0 i}(x, y, t) \\
w_{i}(x, y, t)
\end{array}\right\}+z_{i}\left\{\begin{array}{c}
\psi_{x}^{i}(x, y, t) \\
\psi_{y}^{i}(x, y, t) \\
0
\end{array}\right\} \quad(i=\text { wall, FRP1, FRP2 })
$$

$$
\begin{aligned}
w_{\mathrm{adh} 1}(x, y, z, t)= & \frac{2 z_{\mathrm{adh} 1}}{h_{\mathrm{adh} 1}^{2}}\left(z_{\mathrm{adh} 1}+\frac{1}{2} h_{\mathrm{adh} 1}\right) w_{\mathrm{wall}}(x, y, t)+\frac{2 z_{\mathrm{adh} 1}}{h_{\mathrm{adh} 1}^{2}}\left(z_{\mathrm{adh} 1}+\frac{1}{2} h_{\mathrm{adh} 1}\right) w_{\mathrm{FRP} 1}(x, y, t) \\
& +\frac{1}{h_{\mathrm{adh} 1}^{2}}\left(h_{\mathrm{adh} 1}^{2}-4 z_{\mathrm{adh} 1}^{2}\right) w_{0}^{\mathrm{adh} 1}(x, y, t),
\end{aligned}
$$

$$
\begin{aligned}
u_{\mathrm{adh} 1}(x, y, z, t)= & \frac{1}{24 h_{\mathrm{adh} 1}^{2}}\left(\left(-3 h_{\mathrm{adh} 1}^{3}+4 z_{\mathrm{adh} 1} h_{\mathrm{adh} 1}^{2}+12 z_{\mathrm{adh} 1}^{2} h_{\mathrm{adh} 1}-16 z_{\mathrm{adh} 1}^{3}\right) w_{\mathrm{FRP} 1}(x, y, t)_{, x}\right. \\
& +\left(3 h_{\mathrm{adh} 1}^{3}+4 z_{\mathrm{adh} 1} h_{\mathrm{adh} 1}^{2}-12 z_{\mathrm{adh} 1}^{2} h_{\mathrm{adh} 1}-16 z_{\mathrm{adh} 1}^{3}\right) w_{\mathrm{wall}}(x, y, t)_{, x} \\
& +\left(32 z_{\mathrm{adh} 1}^{3}-8 z_{\mathrm{adh} 1} h_{\mathrm{adh} 1}^{2}\right) w_{0}^{\mathrm{adh} 1}(x, y, t)_{, x} \\
& -12 h_{\mathrm{adh} 1}\left(h_{\mathrm{FRP} 1}\left(z_{\mathrm{adh} 1}-\frac{1}{2} h_{\mathrm{adh} 1}\right) \psi_{x}^{\mathrm{FRP} 1}(x, y, t)+h_{\mathrm{wall}}\left(z_{\mathrm{adh} 1}+\frac{1}{2} h_{\mathrm{adh} 1}\right) \psi_{x}^{\text {wall }}(x, y, t)\right. \\
& \left.\left.+\left(2 z_{\mathrm{adh} 1}-h_{\mathrm{adh} 1}\right) u_{0 \mathrm{FRP} 1}(x, y, t)-2\left(z_{\mathrm{adh} 1}+\frac{1}{2} h_{\mathrm{adh} 1}\right) u_{0 \mathrm{wall}}(x, y, t)\right)\right),
\end{aligned}
$$

$v_{\mathrm{adh} 1}(x, y, z, t)=\frac{1}{24 h_{\mathrm{adh} 1}^{2}}\left(\left(-3 h_{\mathrm{adh} 1}^{3}+4 z_{\mathrm{adh} 1} h_{\mathrm{adh} 1}^{2}+12 z_{\mathrm{adh} 1}^{2} h_{\mathrm{adh} 1}-16 z_{\mathrm{adh} 1}^{3}\right) w_{\mathrm{FRP} 1}(x, y, t), y\right.$

$+\left(3 h_{\mathrm{adh} 1}^{3}+4 z_{\mathrm{adh} 1} h_{\mathrm{adh} 1}^{2}-12 z_{\mathrm{adh} 1}^{2} h_{\mathrm{adh} 1}-16 z_{\mathrm{adh} 1}^{3}\right) w_{\mathrm{wall}}(x, y, t), y$

$+\left(-8 z_{\mathrm{adh} 1} h_{\mathrm{adh} 1}^{2}+32 z_{\mathrm{adh} 1}^{3}\right) w_{0}^{\mathrm{adh} 1}(x, y, t), y$

$-12 h_{\mathrm{adh} 1}\left(h_{\mathrm{FRP} 1}\left(z_{\mathrm{adh} 1}-\frac{1}{2} h_{\mathrm{adh} 1}\right) \psi_{y}^{\mathrm{FRP} 1}(x, y, t)+h_{\mathrm{wall}}\left(z_{\mathrm{adh} 1}+\frac{1}{2} h_{\mathrm{adh} 1}\right) \psi_{y}^{\mathrm{wall}}(x, y, t)\right.$

$\left.\left.+\left(2 z_{\mathrm{adh} 1}-h_{\mathrm{adh} 1}\right) v_{0 \mathrm{FRP} 1}(x, y, t)-2\left(z_{\mathrm{adh} 1}+\frac{1}{2} h_{\mathrm{adh} 1}\right) v_{0 \mathrm{wall}}(x, y, t)\right)\right)$,

$$
\begin{aligned}
w_{\mathrm{adh} 2}(x, y, z, t)= & \frac{2 z_{\mathrm{adh} 2}}{h_{\mathrm{adh} 2}^{2}}\left(z_{\mathrm{adh} 2}+\frac{1}{2} h_{\mathrm{adh} 2}\right) w_{\mathrm{FRP} 2}(x, y, t)+\frac{2 z_{\mathrm{adh} 2}}{h_{\mathrm{adh} 2}^{2}}\left(z_{\mathrm{adh} 2}+\frac{1}{2} h_{\mathrm{adh} 2}\right) w_{\mathrm{wall}}(x, y, t) \\
& +\frac{1}{h_{\mathrm{adh} 2}^{2}}\left(h_{\mathrm{adh} 2}^{2}-4 z_{\mathrm{adh} 2}^{2}\right) w_{0}^{\mathrm{adh} 2}(x, y, t)
\end{aligned}
$$

$$
\begin{aligned}
u_{\mathrm{adh} 2}(x, y, z, t)= & \frac{1}{24 h_{\mathrm{adh} 2}^{2}}\left(\left(-3 h_{\mathrm{adh} 2}^{3}+4 z_{\mathrm{adh} 2} h_{\mathrm{adh} 2}^{2}+12 z_{\mathrm{adh} 2}^{2} h_{\mathrm{adh} 2}-16 z_{\mathrm{adh} 2}^{3}\right) w_{\mathrm{wall}}(x, y, t)_{, x}\right. \\
& +\left(3 h_{\mathrm{adh} 2}^{3}+4 z_{\mathrm{adh} 2} h_{\mathrm{adh} 2}^{2}-12 z_{\mathrm{adh} 2}^{2} h_{\mathrm{adh} 2}-16 z_{\mathrm{adh} 2}^{3}\right) w_{\mathrm{FRP} 2}(x, y, t)_{, x} \\
& +\left(-8 z_{\mathrm{adh} 2} h_{\mathrm{adh} 2}^{2}+32 z_{\mathrm{adh} 2}^{3}\right) w_{0}^{\mathrm{adh} 2}(x, y, t) \\
& -12 h_{\mathrm{adh} 2}\left(h_{\mathrm{wall}}\left(z_{\mathrm{adh} 2}-\frac{1}{2} h_{\mathrm{adh} 2}\right) \psi_{x}^{\mathrm{wall}}(x, y, t)+\frac{1}{2} h_{\mathrm{adh} 2}\right) \psi_{x}^{\mathrm{FRP} 2}(x, y, t) \\
& \left.+\left(2 z_{\mathrm{adh} 2}-h_{\mathrm{adh} 2}\right) u_{0 \mathrm{wall}}(x, y, t)+h_{\mathrm{FRP} 2}\left(z_{\mathrm{adh} 2}-2\left(z_{\mathrm{adh} 2}+\frac{1}{2} h_{\mathrm{adh} 2}\right) u_{0 \mathrm{FRP} 2}(x, y, t)\right)\right),
\end{aligned}
$$




$$
\begin{aligned}
v_{\mathrm{adh} 2}(x, y, z, t)= & \frac{1}{24 h_{\mathrm{adh} 2}^{2}}\left(\left(-3 h_{\mathrm{adh} 2}^{3}+4 z_{\mathrm{adh} 2} h_{\mathrm{adh} 2}^{2}+12 z_{\mathrm{adh} 2}^{2} h_{\mathrm{adh} 2}-16 z_{\mathrm{adh} 2}^{3}\right) w_{\mathrm{wall}}(x, y, t)_{, y}\right. \\
& +\left(3 h_{\mathrm{adh} 2}^{3}+4 z_{\mathrm{adh} 2} h_{\mathrm{adh} 2}^{2}-12 z_{\mathrm{adh} 2}^{2} h_{\mathrm{adh} 2}-16 z_{\mathrm{adh} 2}^{3}\right) w_{\mathrm{FRP} 2}(x, y, t)_{, y} \\
& +\left(-8 z_{\mathrm{adh} 2} h_{\mathrm{adh} 2}^{2}+32 z_{\mathrm{adh} 2}^{3}\right) w_{0}^{\mathrm{adh} 2}(x, y, t)_{, y} \\
& -12 h_{\mathrm{adh} 2}\left(h_{\mathrm{FRP} 1}\left(z_{\mathrm{adh} 2}-\frac{1}{2} h_{\mathrm{adh} 2}\right) \psi_{y}^{\mathrm{wall}}(x, y, t)+\frac{1}{2} h_{\mathrm{adh} 2}\right) \psi_{y}^{\mathrm{FRP} 2}(x, y, t) \\
& \left.+\left(2 z_{\mathrm{adh} 2}-h_{\mathrm{adh} 2}\right) v_{0 \mathrm{wall}}(x, y, t)+h_{\mathrm{wall}}\left(z_{\mathrm{adh} 2}-2\left(z_{\mathrm{adh} 2}+\frac{1}{2} h_{\mathrm{adh} 2}\right) v_{0 \mathrm{FRP} 2}(x, y, t)\right)\right),
\end{aligned}
$$

where $z_{i}$ is measured from the mid-surface of each layer, $h_{\mathrm{adh} 1}$ and $h_{\mathrm{adh} 2}$ are the thicknesses of the adhesive layers (Figure 3a). The unknown functions of $x, y$, and $t$, which appear on the right hand side of Equations (1)-(7), are approximated by the finite element shape functions $N(x, y)$ and the time dependent nodal displacement $d(t)$. More details on the derivation of the displacement fields, and particularly the displacement fields of the adhesive layers, are found in [Elmalich and Rabinovitch 2012a].

The finite element formulation takes a standard form that reads:

$$
\boldsymbol{M} \ddot{\boldsymbol{d}}+\boldsymbol{C} \dot{\boldsymbol{d}}+\boldsymbol{K} \boldsymbol{d}-\boldsymbol{F}(t)=\mathbf{0}
$$

where $\boldsymbol{M}$ is the mass matrix, $\boldsymbol{K}$ is the stiffness matrix, $\boldsymbol{C}$ is the damping matrix, and $\boldsymbol{F}(t)$ is the vector of external forces. The matrices $\boldsymbol{M}$ and $\boldsymbol{K}$ and the vector $\boldsymbol{F}(t)$ are assembled using the elemental matrices and the standard assembly procedure. The damping matrix $C$ is synthesized following the Rayleigh damping approach:

$$
\boldsymbol{C}=a_{0} \boldsymbol{M}+a_{1} \boldsymbol{K}
$$

where the constants $a_{0}$ and $a_{1}$ are determined based on prescribed damping ratios that correspond to two of the vibration modes (see, for example, [Chopra 2001]).

3.2. FE model of the strengthened AAC wall. A schematic illustration of the FE model of the tested wall, its geometry, and the boundary conditions are shown in Figure 4. The thick lines at the top of the wall represent the upper steel beam. This beam is modeled using standard first order shear deformable 3D beam elements. The thin lines in Figure 4 represent the system of cables. Each cable is modeled as a longitudinal bar element with equivalent elastic and mass properties. Since the cables are pre-tensioned,

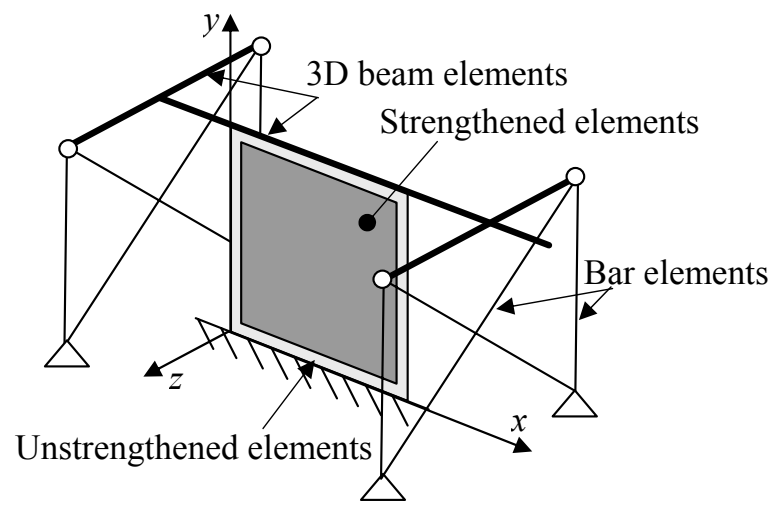

Figure 4. Schematic description of the FE model of the test setup. 
the ability of the bar elements to resist compression is attributed to a reduction of the level of pre-tension in the cable and not expected to affect the comparison with the experiments. The diameter of the equivalent cross section is taken as $2.5 \mathrm{~mm}$. This value is estimated based on the measured out-of-plane natural frequencies of the unstrengthened wall and the cables themselves and it reduces the nominal $3.2 \mathrm{~mm}$ diameter cross section due to the mass and the softening effects introduced by the tensioning devices, the load cells, and the connectors along the cable.

The dark gray area in Figure 4 represents the FRP strengthened region and the light gray area represents a $35 \mathrm{~mm}$ wide unstrengthened region at the perimeter of the patch. The FRP strengthened region is modeled using the specially tailored elements developed in [Elmalich and Rabinovitch 2012a] and briefly discussed above. The $35 \mathrm{~mm}$ wide unstrengthened regions at the perimeter are modeled using first order shear deformable shell elements with four nodes. The entire combination of elements (3D beam elements, 3D bar elements, shear deformable shell elements, and specially tailored elements) is assembled together to a unified FE model. In order to reduce the computational load, a substructuring procedure with superelements is adopted (see, for example, [Zienkiewitch 1977]). The application of the superelement substructuring approach to the specially tailored FE formulation of the FRP strengthened wall is discussed in [Elmalich and Rabinovitch 2012c]. In the present work, the substructuring procedure uses the classical Guyan reduction algorithm [Guyan 1965]. The superelement approach is applied to the $2 \mathrm{D}$ wall elements and the most refined mesh used here includes 26 by 28 superelements in the $x$ and $y$ directions, respectively. Each superelement is composed of 9 by 9 basic elements of the type derived in [Elmalich and Rabinovitch 2012a]. In the substructure level, each superelement includes 36 boundary nodes that replace a mesh of "regular" elements with 100 nodes. In the global scale, a mesh of superelements with 12,863 nodes replaces a mesh of "regular" basic elements with 59,455 nodes.

The dynamic analysis includes the assessment of natural frequencies and vibration modes as well as time history analysis. The first type of analysis uses the eigenvalue procedure implemented in MATLAB and the second one uses Newmark's method. The time step used in Newmark's method is determined based on the natural frequencies of the unstrengthened wall. If necessary, it is further refined after assessing the stability and the convergence characteristics of the numerical solution (A discussion of the stability and convergence of the high order finite element analysis appears in [Elmalich and Rabinovitch 2012a; 2012b; 2012c]). The time history analysis uses a Rayleigh damping with $10 \%$ damping ratio for the first and the third modes evaluated by the eigenvalue analysis of the unstrengthened panel. The relatively high damping ratio reflects the damping of the wall specimen but also the damping involved with the test setup.

3.3. Material properties. The material properties reported by the manufacturers of the materials are summarized in Table 1. The GFRP layer is assumed orthotropic with a design thickness of $0.065 \mathrm{~mm}$. The thickness of the adhesive layers is estimated as $2 \mathrm{~mm}$. This value also includes the thin resin saturated layer that forms in the outer shell of the AAC blocks.

The homogenized elastic and mechanical properties of the AAC panel play a critical role in the analysis of the dynamic response. Therefore, the elastic properties of the masonry assembly are experimentally evaluated. This is achieved using a diagonal compression test of the AAC unstrengthened panel. The schematic layout of this test is illustrated in Figure 5. The specimen that was used in the dynamic shake table experiments is tested to failure. The corners of the panel are trimmed in order to form a loading 


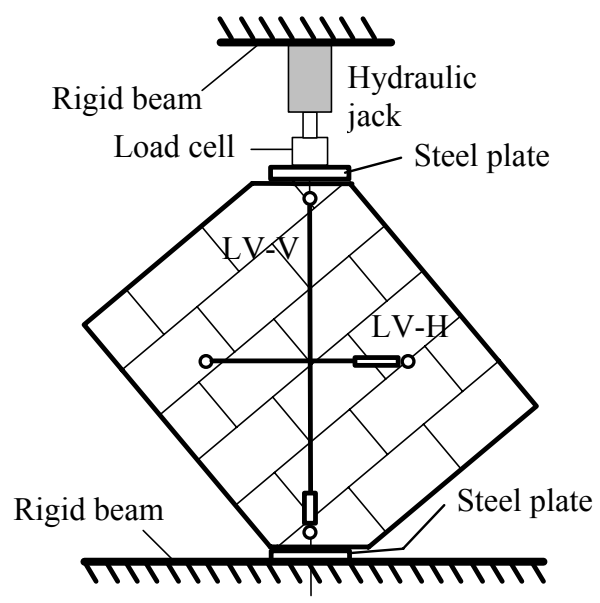

Figure 5. Test setup for the diagonal compression test of the unstrengthened panel.

plane perpendicular to the diagonal of the wall. The specimen is compressed using a hydraulic jack and the response is monitored using LVDTs and a load cell as shown in Figure 5.

A plot of the compressive force versus the averaged vertical strain (the shortening measured by LVDT divided by its length) is shown in Figure 6. The force-strain curve reveals a linear phase up to a strain level of about $0.01 \%$. At this point, a jump in the level of the force is observed. The jump is followed by another linear and much longer phase up to failure. The slope of the second linear phase is almost identical to the slope of the first phase. The slope of this linear phase and the results of numerical simulation of the static compression test are used for the assessment of the homogenized elastic modulus of the masonry assembly. Due to the geometry of the specimen, the testing along the diagonal, and the impact of this layout on the direct conversion of the measured load versus measured shortening (or averaged strain) into a stress-strain curve, the homogenized elastic modulus is calibrated using the FE model. This is achieved by matching the numerically predicted slope of the load-versus average strain curve with the experimental one. Based on this procedure, the homogenized elastic modulus equals

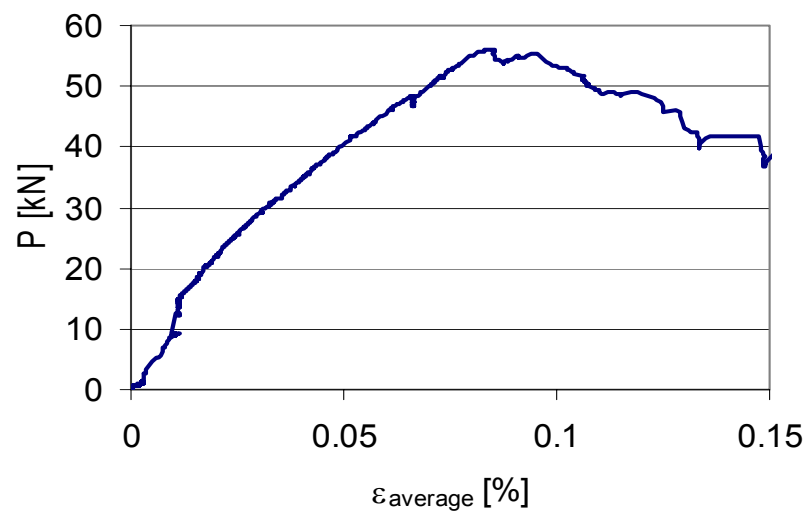

Figure 6. Diagonal compression test of the unstrengthened AAC panel: force versus average strain. 
$1500 \mathrm{MPa}$. This value is close to the lower value reported by the manufacturer for the AAC block (see Table 1). The calibrated value is also within the range of elastic moduli reported in the literature for AAC blocks of similar dry densities (see, for example, [Narayanan and Ramamurthy 2000]). The failure of the tested panel was controlled by splitting of the AAC blocks in the walls plane. Failure of the mortar joints was not detected. This observation, which differs from the classical mode of failure of masonry walls built of heavy natural stone or concrete masonry blocks and mortar joints, supports the consideration of the AAC masonry specimen as a homogenized isotropic and elastic medium and the corresponding assumptions used in the formulation.

\section{Free vibration response and model validation}

In this section, the natural frequencies and vibration modes are experimentally detected and compared with the ones determined by the FE model. The numerical natural frequencies and mode shapes are determined by solving the eigenvalue problem associated with the homogeneous undamped form of (9). In order to verify the convergence of the numerical solution, four meshes are examined. The numerically detected frequencies are listed in Table 2 and the vibration modes are shown in Figure 7. In order to allow a quantitative comparison between the modes, they are normalized to yield the same level of peak potential energy. For clarity of the figure, the displacements in Figure 7 are scaled up by a factor of 100 .

The experimental natural frequencies are estimated using a Fast Fourier Transforms (FFT) of the time dependent signals measured by the various sensors in response to the two types of impulse loadings. The FFT plots present the complex result of the transformation multiplied by its complex conjugate. For clarity, the values are normalized with respect to the peak value detected in the figure's frequency range.

The identification of the experimental mode shapes is a more challenging task. The experimental detection of the mode shapes is based on the readings of various sensors and mainly of the readings of the accelerometers mounted on the top beam, the strain gauges mounted on the FRP layer, and the eight load cells mounted on the cables. In some cases, linear combinations of the directly measured signals are also examined. For example, averaging the readings of the $z$ component of accelerations measured above the top east and top west corners of the wall (ACC211 and ACC212) yields a time domain signal that corresponds to the out-of-plane ( $z$ direction) movement of the upper beam. This signal is used for identifying mode shapes that are governed by out-of-plane flexure of the wall. The difference between the readings of the same two accelerometers divided by the distance between them defines an angular acceleration of the upper beam. This signal is used for identifying mode shapes that are governed by

\begin{tabular}{|c|c|c|c|c|c|}
\hline \multirow[t]{2}{*}{ Mode } & \multirow{2}{*}{$\begin{array}{c}\text { Experiment } \\
{[\mathrm{Hz}]}\end{array}$} & \multicolumn{4}{|c|}{ Analysis [Hz] } \\
\hline & & $\begin{array}{c}\text { Mesh A: } \\
\text { 7,956 DOFs }\end{array}$ & $\begin{array}{c}\text { Mesh B: } \\
\text { 10,846 DOFs }\end{array}$ & $\begin{array}{c}\text { Mesh C: } \\
\text { 14,178 DOFs }\end{array}$ & $\begin{array}{c}\text { Mesh D: } \\
\text { 218,671 DOFs }\end{array}$ \\
\hline 1 & 20.8 & 22.415 & 22.402 & 22.394 & 22.366 \\
\hline 2 & 27.2 & 30.176 & 30.171 & 30.168 & 30.158 \\
\hline 3 & $68.0-69.0$ & 67.089 & 67.079 & 67.073 & 67.046 \\
\hline
\end{tabular}

Table 2. Experimental and numerical results for the first three natural frequencies. 

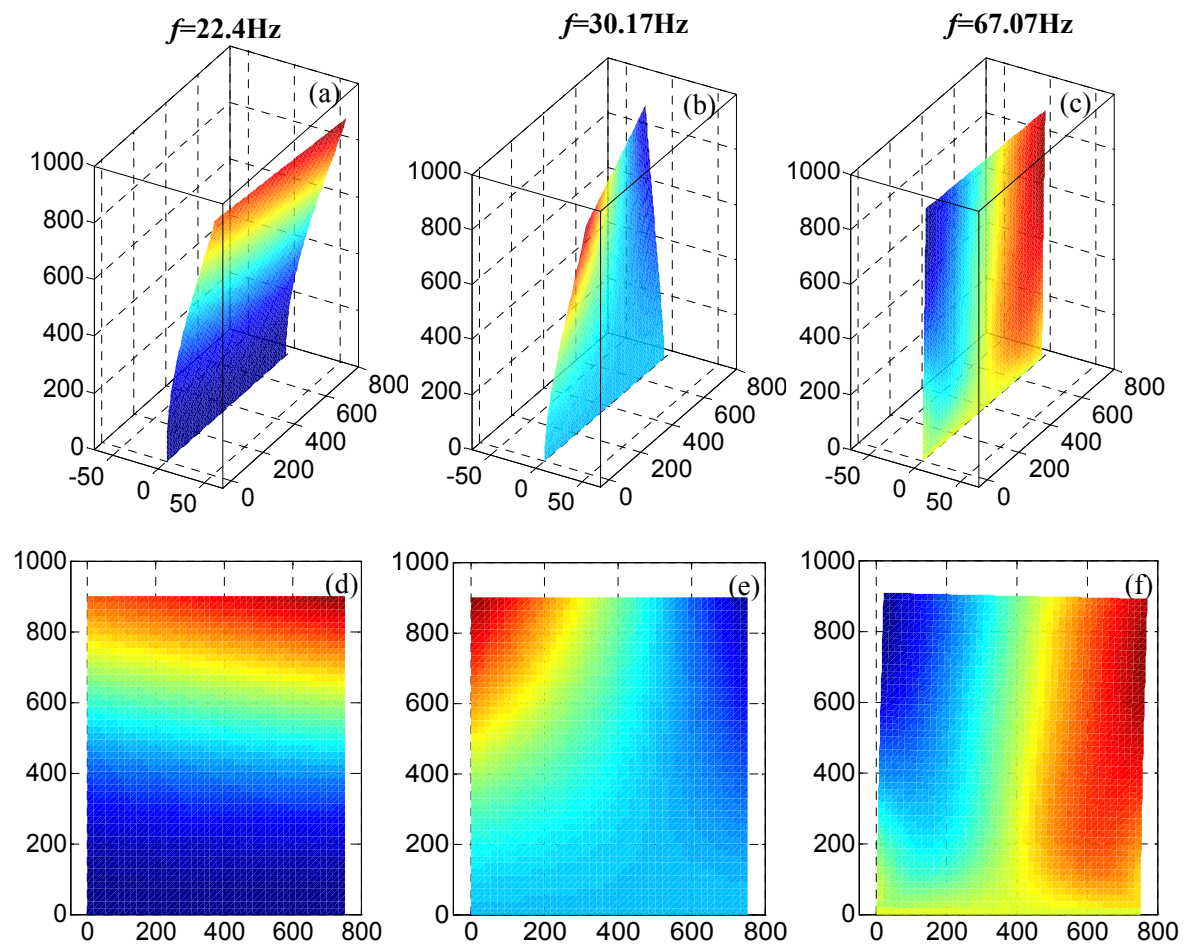

Figure 7. Vibration modes of the strengthened panel detected by the FE analysis and normalized for equal potential energy (the deformed shapes are scaled up by a factor of 100): (a) axonometric view, first mode; (b) axonometric view, second mode; (c) axonometric view, third mode; (d) $x-y$ view, first mode; (e) $x-y$ view, second mode; (f) $x-y$ view, third mode.

twist of the wall and rotation of the top beam about the $y$ axis. More experimental data is extracted by looking into linear combinations of the signals recorded by the load cells mounted on the cables.

The $20.8 \mathrm{~Hz}$ frequency detected in the experiment and listed in the first line of Table 2 is attributed to the out-of-plane flexural mode. To support this hypothesis, the average of the out-of-plane accelerations ( $z$ direction) at the top corners of the panel (ACC211, ACC212) is examined in Figure 8. The signal is defined by

$$
\overline{\operatorname{ACC} z(t)}=(\operatorname{ACC} 211(t)+A C C 212(t)) / 2,
$$

where $\overline{A C C z(t)}$ is the averaged signal and $A C C 211(t), A C C 212(t)$ are the readings of the accelerometers.

The time domain responses of $\overline{A C C Z(t)}$ appear in Figure $8 \mathrm{a}$ and reveal a cyclic structural response with a slight low frequency beating. The time domain response shows that the differences between one experiment and another and between the two types of impulsive loading (sudden breaking of the shake table and hammering on the top beam) are very small. This indicates good repeatability. The frequency domain results of the averaged accelerations signal $\overline{A C C z(t)}$ appear in Figure $8 \mathrm{~b}$ and reveal a significant peak at a frequency of $20.8 \mathrm{~Hz}$. The presence of this peak in the averaged signal attributes 

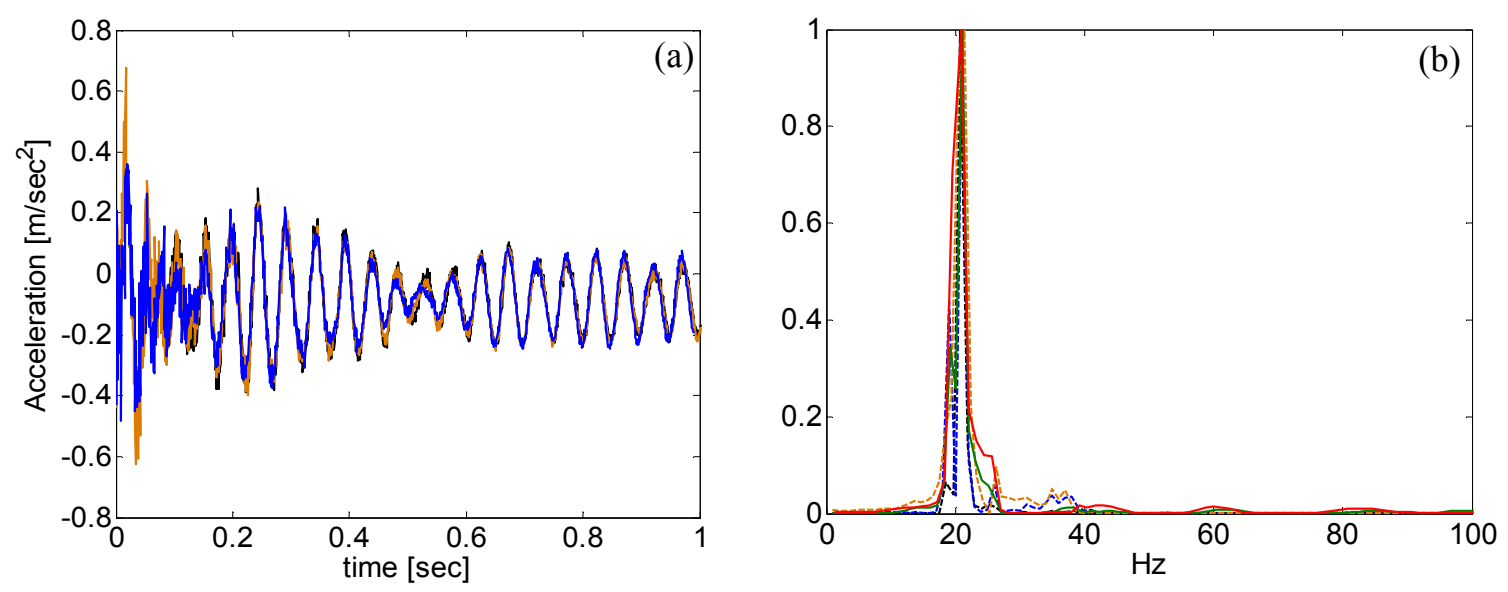

Figure 8. Response of the FRP strengthened masonry wall to in-plane impulse load: (a) time domain response of the averaged out-of-plane acceleration $\overline{A C C z(t)}$; (b) normalized frequency domain response of $\overline{A C C z(t)}$. Legend: — impulse load introduced through the shake table; - - - impulse load introduced through top beam. Each color refers to a different test.

this frequency to an out-of-plane flexure mode. Another observation that supports the hypothesis that the $20.8 \mathrm{~Hz}$ frequency corresponds to the out-of-plane flexure mode is found in the average of the lateral components of the variations in the tensile forces in the diagonal cables at the two stiffening planes. This signal is defined by

$$
\overline{\Delta F_{z \mathrm{DIAG}}(t)}=(\Delta L C 3(t)+\Delta L C 4(t)+\Delta L C 7(t)+\Delta L C 8(t)) \cdot \cos (\alpha) / 4,
$$

where $\Delta L C i(t)=L C i(t)-L C i(0)$ is the time domain signal of the variation of the force in the $i$-th load cell, $L C i(t)(i=1 \ldots 8)$ is the signal measured by the $i$-th load cell, $L C i(0)$ is the reading of the $i$-th load cell at $t=0$, and $\alpha=0.866 \mathrm{rad}$ is the inclination angle of the diagonal cables. The frequency domain response of $\overline{\Delta F_{z \text { DIAG }}(t)}$ is shown in Figure 9. This measure, which corresponds to out-of-plane movement of the top of the wall, also reveals one major peak at a frequency of $20.8 \mathrm{~Hz}$. The correlation between the two FFT analyses attributes the $20.8 \mathrm{~Hz}$ frequency to the out-of-plane flexure mode.

The first natural frequency predicted by the numerical model equals $22.37 \mathrm{~Hz}$ and the corresponding mode, which appears in Figures $7 \mathrm{a}$ and $7 \mathrm{~d}$, is governed by out-of-plane flexure and out-of-plane movement of the upper beam. The numerically evaluated frequency is in good agreement with the experimental one and the model well captures the first out-of-plane mode (including the slight bending-twist coupling due to the asymmetric mass distribution of the upper beam; see Figures 1 and 7). The numerical values also point at convergence of the numerical solution with refinement of the mesh. This convergence and the agreement with the experiments support the validity of the FE model.

In physical terms, the experimental characterization of the first mode highlights the coupling of the in-plane and out-of-plane responses. The triggering of out-of-plane vibrations due to the in-plane impulsive excitation demonstrates this inevitable coupling. This observation implies that in many cases, the 


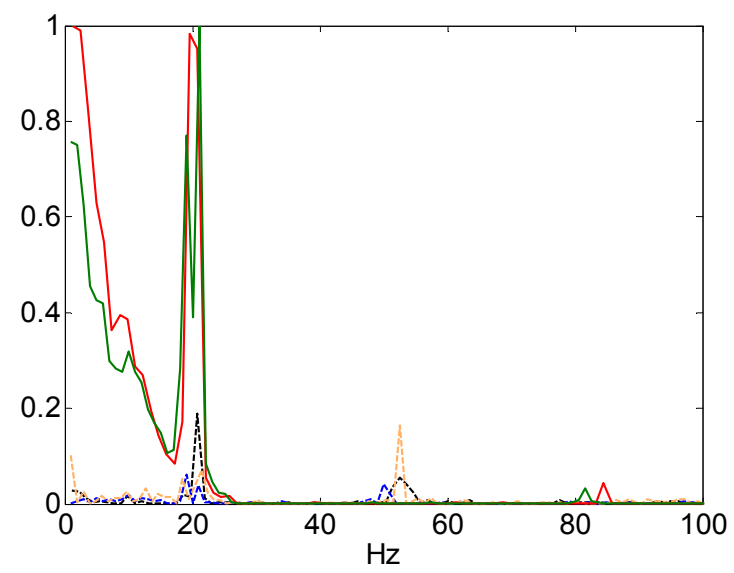

Figure 9. Response of the FRP strengthened masonry wall to in-plane impulse load: normalized frequency domain response of the averaged out-of-plane component in the diagonal cables $\overline{\Delta F_{z \operatorname{DIAG}}(t)}$. Legend: - impulse load introduced through the shake table; - - - impulse load introduced through top beam. Each color refers to a different test.

decoupling of the dynamic handling of the wall to a pure in-plane case and a pure out-of-plane case may be involved with loss of important physical information.

The $27.2 \mathrm{~Hz}$ frequency reported in the second line of Table 2 is attributed to the twisting mode of the wall. This mode, which is illustrated based on the analysis in Figure 7b, is governed by rotation of the top beam about the $y$ axis. In the experiment, this mode is reflected by the angular acceleration of the top beam. This signal is defined by

$$
\operatorname{ACC}_{\theta y}(t)=(A C C 211(t)-A C C 212(t)) / L_{\mathrm{ACC}},
$$

where $L_{\mathrm{ACC}}=750 \mathrm{~mm}$ is the distance between the two accelerometers (see Figure 1). The time history signal of $A C C_{\theta y}(t)$ appears in Figure 10a and reveals a high level of repeatability and minor differences between one test and another and between one testing method and another. The frequency domain transform of the signal appear in Figure 10b and reveals one major peak at a frequency of $27.2 \mathrm{~Hz}$. The presence of this peak implies that this experimentally detected frequency corresponds to the second, twist governed, mode shown in Figures 7b,e. In order to further support this observation, the difference between the lateral components of the forces in the diagonal cables is examined. This signal, which is studied in Figure 11, is defined as by

$$
\Delta \Delta F_{z \mathrm{DIAG}}(t)=(\Delta L C 3(t)+\Delta L C 4(t)-\Delta L C 7(t)-\Delta L C 8(t)) \cdot \cos (\alpha)
$$

Figure 11 indicates that the normalized FFT of the response to the impulse load at the top beam includes a clear peak at a frequency that is close to the one observed in the frequency analysis of the angular acceleration (Figure 10b). The FFT analysis of the response to impulsive base motion and the larger amount of energy input it introduces include this peak. However, it also includes additional and more significant ones at higher frequencies.

The comparison between the FE result $(30.17 \mathrm{~Hz})$ and the experimental results $(27.2 \mathrm{~Hz})$ reveals a reasonable agreement. The differences, and mainly the fact that the experimental natural frequencies are 

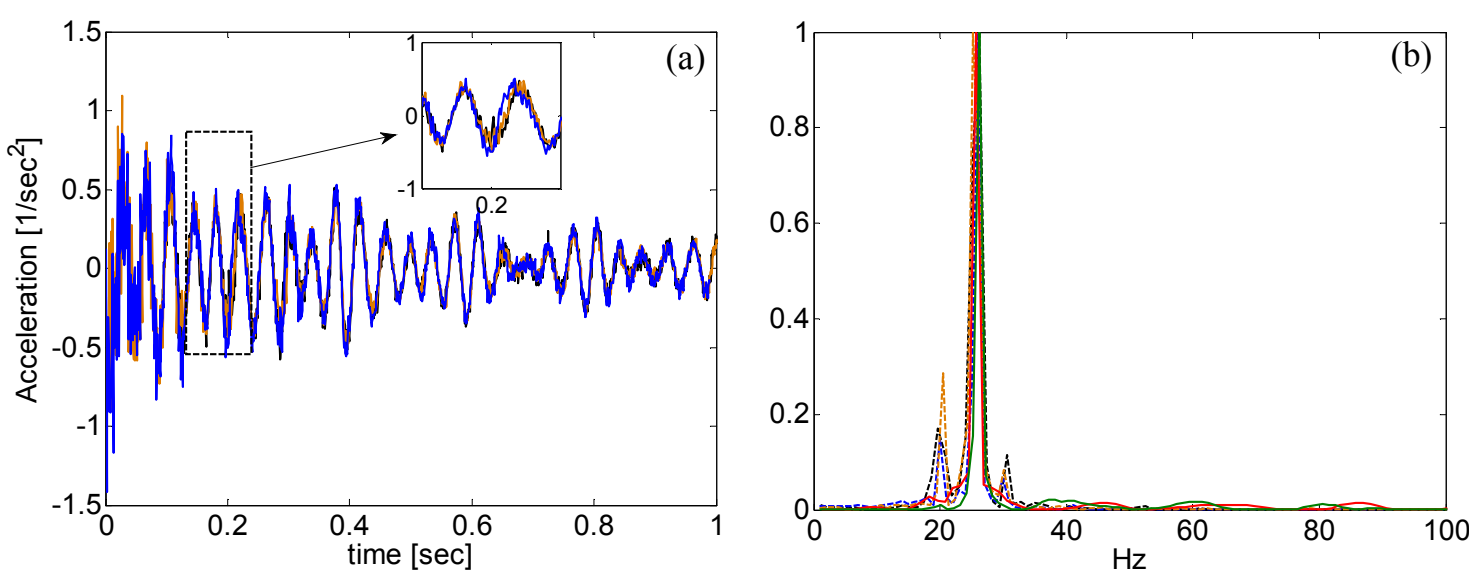

Figure 10. Response of the FRP strengthened masonry wall to in-plane impulse load: (a) time domain response of the angular acceleration $A C C_{\theta y}(t)$; (b) normalized frequency domain response of $A C C_{\theta y}(t)$. Legend: - impulse load introduced through the shake table; - - - impulse load introduced through top beam. Each color refers to a different test.

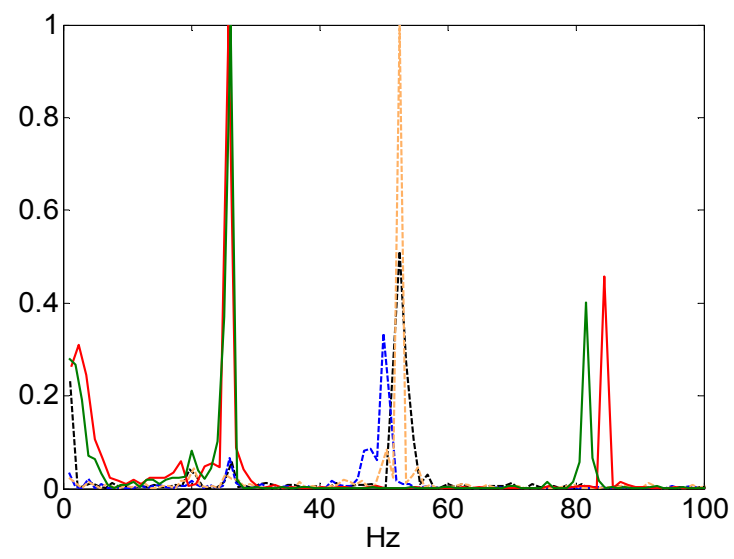

Figure 11. Response of the FRP strengthened masonry wall to in-plane impulse load: normalized frequency domain response of $\Delta \Delta F_{z \text { DIAG }}(t)$. Legend: - impulse load introduced through the shake table; - - - impulse load introduced through top beam. Each color refers to a different test.

lower than the analytical ones, are attributed to the range of inevitable imperfections that are part of the experiment but not accounted for in the "sterile" numerical model. Nevertheless, the agreement between the FE analysis and the experimental results, both in terms of the natural frequency and in terms of the vibration mode, support the validity of the FE model.

The in-plane response of the tested specimen is studied in Figure 12. The time domain and the frequency domain distributions of the in-plane acceleration ( $x$ direction) at the top beam (ACC99) are shown in Figures 12a,b, respectively. The major peaks are observed at a frequency of $17 \mathrm{~Hz}$ and at a band 
that ranges from 35 to $37 \mathrm{~Hz}$. The first value is attributed to interaction with the shake table itself. In order to gain more insight into the source of the second peak $(35-37 \mathrm{~Hz})$ and its relation to the in-plane behavior of the panel, the differential forces in the vertical cables are examined. This combination of signals is defined by

$$
\Delta \Delta F_{y \operatorname{VERT}}(t)=\Delta L C 1(t)+\Delta L C 2(t)-\Delta L C 5(t)-\Delta L C 6(t)
$$

This combination aims to examine the rocking behavior of the upper beam, which is part of the inplane response mode, see Figure $7 \mathrm{c}$ and Figure $7 \mathrm{f}$. The time domain response of this combination appears in Figure $12 \mathrm{c}$ and reveals a good repeatability. The frequency domain response appears in Figure 12d and reveals peaks at a range of frequencies between 35 to $37 \mathrm{~Hz}$.
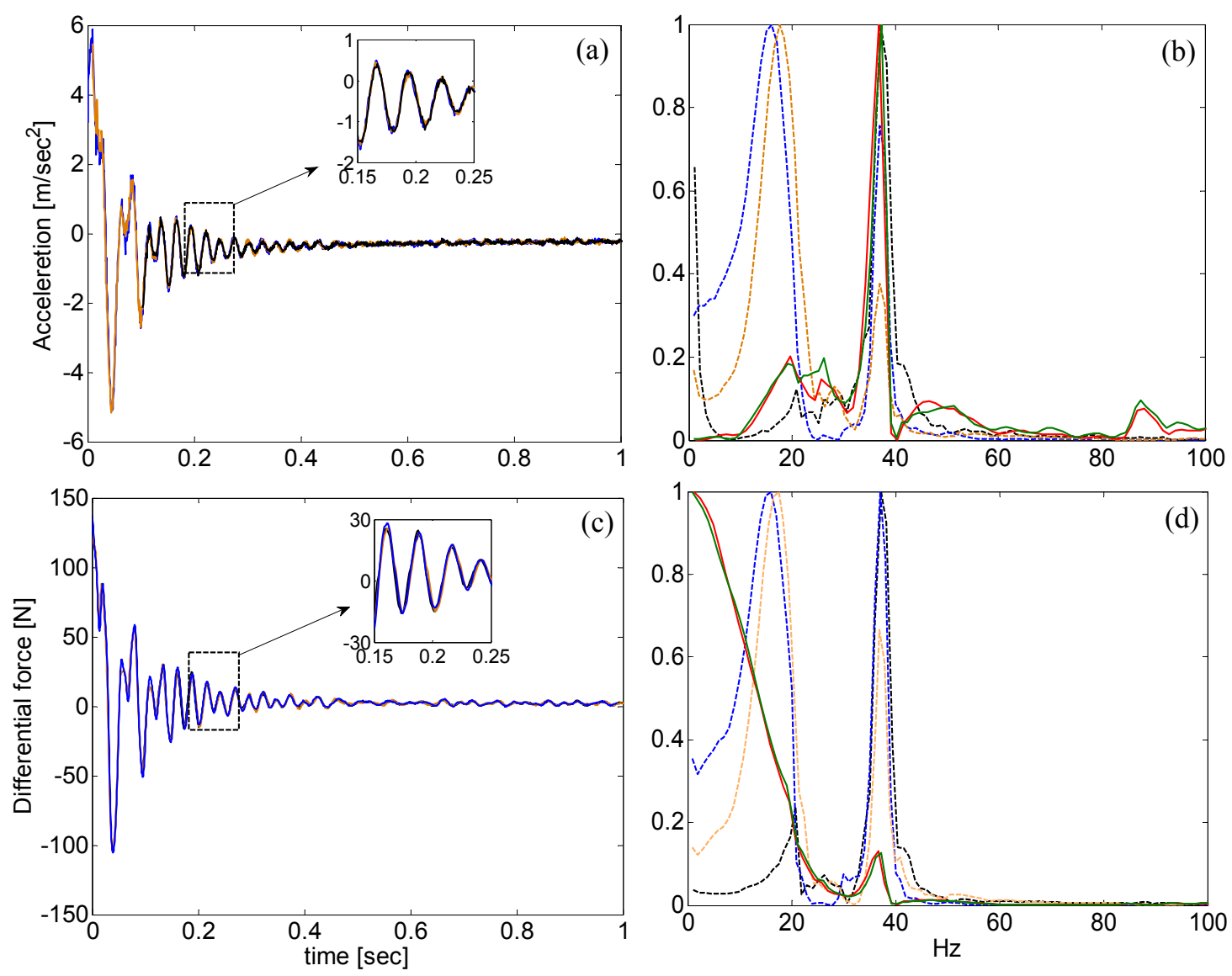

Figure 12. Response of the FRP strengthened masonry wall to in-plane impulse load: (a) time domain response of the in-plane acceleration; (b) normalized frequency domain response of the in-plane acceleration; (c) time domain response of $\Delta \Delta F_{y \mathrm{VERT}}(t)$; (d) normalized frequency domain response of $\Delta \Delta F_{y \mathrm{VERT}}(t)$. Legend: - impulse load introduced through the shake table; - - - impulse load introduced through top beam. Each color refers to a different test. 

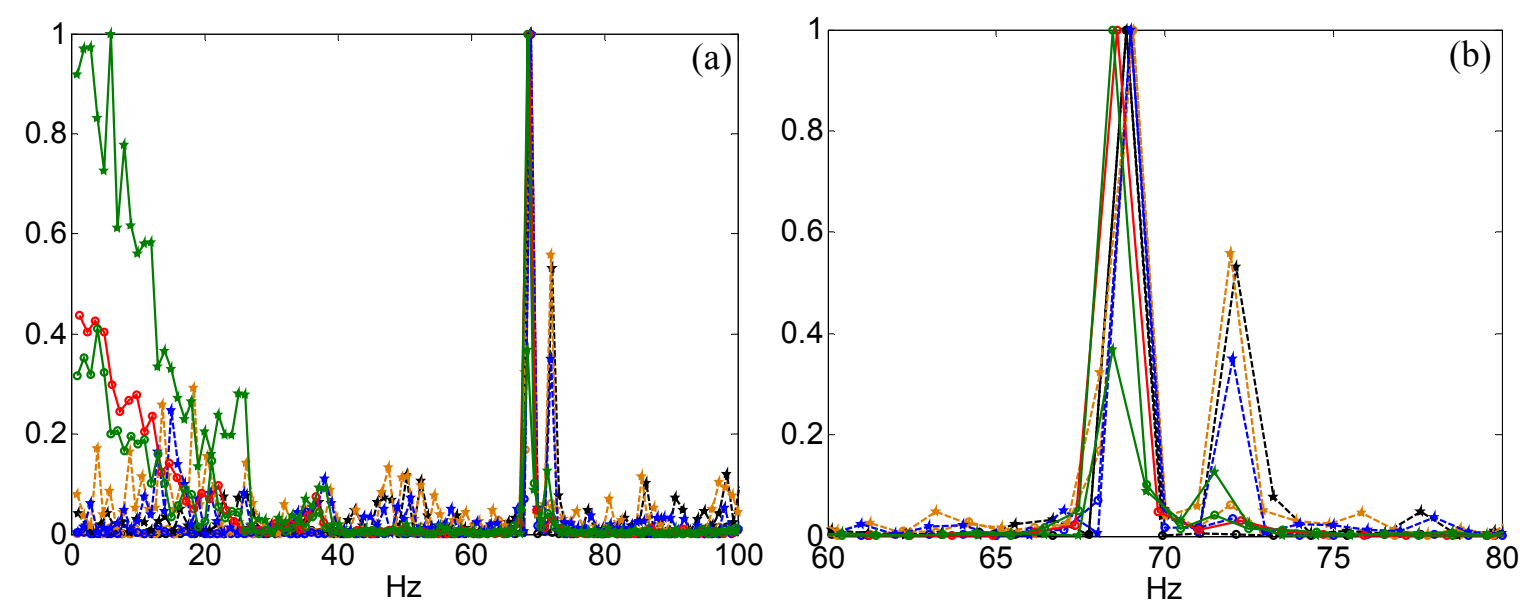

Figure 13. Response of the FRP strengthened masonry wall to in-plane impulse load: normalized frequency domain response of the short strain gages on the north face: (a) full range; (b) zoom on 60-80 Hz. Legend: diagonal strain gage, shake table movement results; vertical strain gage, shake table movement results; diagonal strain gage, top beam loading results; vertical strain gage, top beam loading results. Each color refers to a different test.

Figure 12 points at a clear range of frequencies. This range is, however, way below the results of the FE analysis, or any other estimation of the expected frequency. In order to examine and settle down this contradiction, additional experimental results are looked at. First, the readings of the strain gages that are mounted on the FRP layer are examined. The frequency domain analysis of the readings of the short strain gages is shown in Figure 13a and a zoom plot on the relevant frequencies band appears in Figure 13b. These experimental results reveal clear peaks at $68-69 \mathrm{~Hz}$.

The experimental result of the in-plane natural frequency detected based on the readings of the strain gages is in good agreement with the third eigenfrequency obtained by the FE analysis (see Table 2). That this frequency is not clearly observed in the FFT analysis of the in-plane acceleration and is not observed in the FFT analysis of the forces in the cables suggests that another, much more dominant, local frequency is involved. It is hypothesized that the $35-37 \mathrm{~Hz}$ band of frequencies is attributed to the natural frequencies of the cables themselves. This hypothesis is examined and possibly supported by looking into two additional experimental observations. First, a free vibration test of the tensioned vertical and diagonal cables is carried out. In this test, each cable is removed from the setup and tensioned between two rigid supports. Then, it is subjected to an impulse load that yields free vibrations. The time domain response is monitored using two accelerometers (tuned to measure the out-of-plane accelerations of the cable) and a load cell. Then the various signals are transformed to the frequency domain. The results of the free vibration tests of the diagonal cables, for different level of pre-tensioning, appear in Figure 14a. They clarify that for the level of tensile force used in the experiment, the natural frequencies of the cable are in the range of $33-35 \mathrm{~Hz}$.

The second experimental observation takes a closer look at the acceleration signal. With the $33-35 \mathrm{~Hz}$ band attributed to the natural frequencies of the cables, the reading of the longitudinal ( $x$ direction) 

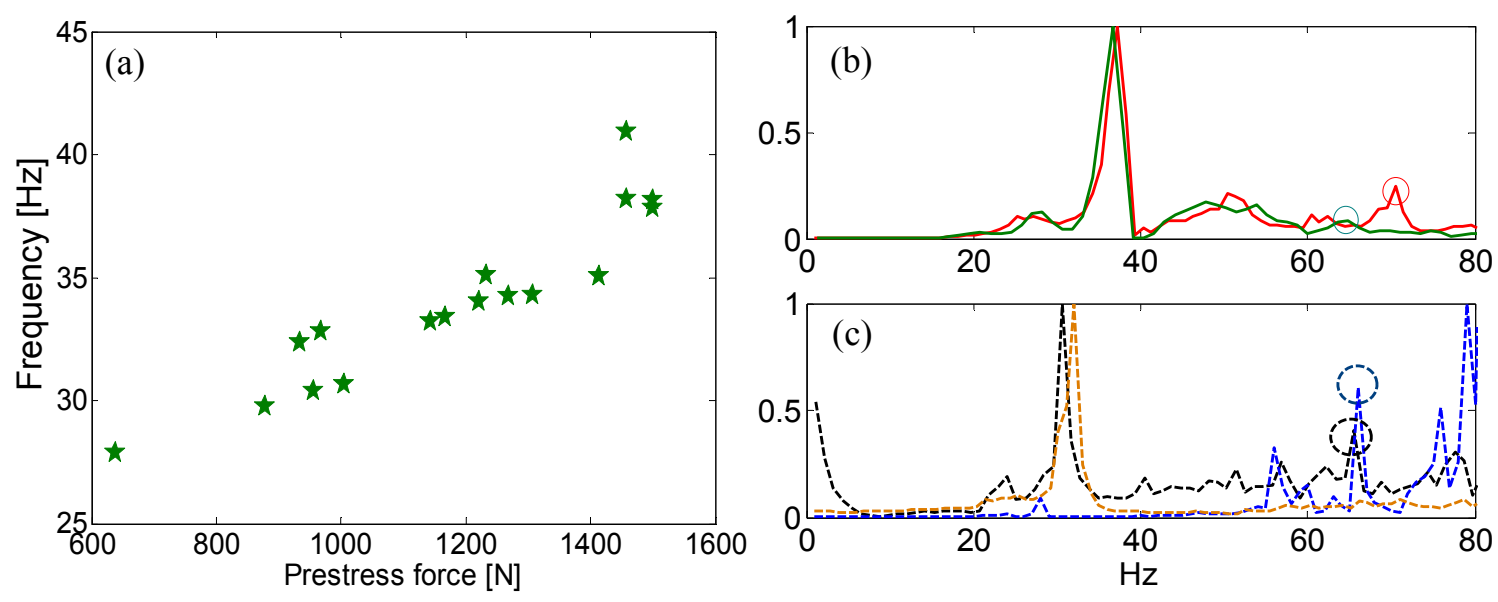

Figure 14. Effect of the localized vibration of the cables: (a) free vibration test of diagonal cable: natural frequency versus tensile force; (b) normalized frequency response of the in-plane acceleration after attenuating the effect the cables - impulse triggered by the shake table; (c) normalized frequency response of the in-plane acceleration after attenuating the effect the cables - impulse triggered through the top beam.

accelerometer $A C C 99(t)$ are examined again but in this case, the effect of the cables on the frequency domain is attenuated. For the experiments conducted by moving the shake table at a constant velocity and then breaking, this is achieved by dividing the FFT representation of the accelerometer signal $A C C 99(t)$ by the FFT representation of the sum of the vertical components of the tensile forces in the cables of the east stiffening plane (the stiffening plane that is closer to the location of the accelerometer). This signal is defined by

$$
\Delta F_{y \mathrm{EAST}: \mathrm{ALL}}=\Delta L C 1(t)+\Delta L C 2(t)+\Delta L C 3(t) \cdot \sin (\alpha)+\Delta L C 4(t) \cdot \sin (\alpha)
$$

The result of this signal appears in Figure 14b. In the experiments conducted by hammering the upper beam in the $x$ direction, the energy input is much smaller than in the case of breaking the shake table and the response detected by the diagonal cables is not sufficiently prominent to yield a meaningful signal. Therefore, for these cases, the last two terms in (15) are omitted and the frequency domain signal of the accelerometer is divided by the frequency domain signal of the vertical cables:

$$
\Delta F_{y \mathrm{EAST}: \mathrm{VERT}}=\Delta L C 1(t)+\Delta L C 2(t)
$$

The FFT representation of the reading of the accelerometer after attenuating the effect of the cables using the signal given by (16) is studied in Figure 14c. This signal, as well as the one shown in Figure 14b, includes peaks in the range of $30-37 \mathrm{~Hz}$, but they also reveal clear peaks in the range of $65-70 \mathrm{~Hz}$. (The relevant peaks are circled in the figures). The $65-70 \mathrm{~Hz}$ frequencies are attributed to the in-plane vibration mode of the FRP strengthened wall. The presence of these peaks indicates that the global in-plane mode is detected by the accelerometer, but it is strongly affected by the localized vibration of the cables. This sensitivity is also affected by the proximity of the accelerometer to the points where the cables connect to the top beam. The strain gages, which are directly mounted on the FRP system, are 
not significantly affected by the localized vibration of the cables. Therefore, the natural frequencies of the cables $(33-37 \mathrm{~Hz})$ are less prominent in the signal of the strain gauges.

The experimental and numerical results discussed above support the identification of the experimentally detected vibration modes and the validity of the FE model. This allows gaining more insight into the effect of each mode on the response of the strengthened wall. It also allows looking into aspects that cannot be directly detected in the experiment. One of these aspects, which directly reflects the interaction between the wall and the FRP, is the evolution of stresses at the interfaces of the adhesive layers. The distributions of the interfacial out-of-plane normal stresses that correspond to the first three modes are shown in Figure 15. Figures 15a,c,e show the stresses at the adhesive-AAC interface and Figures 15b,d,f
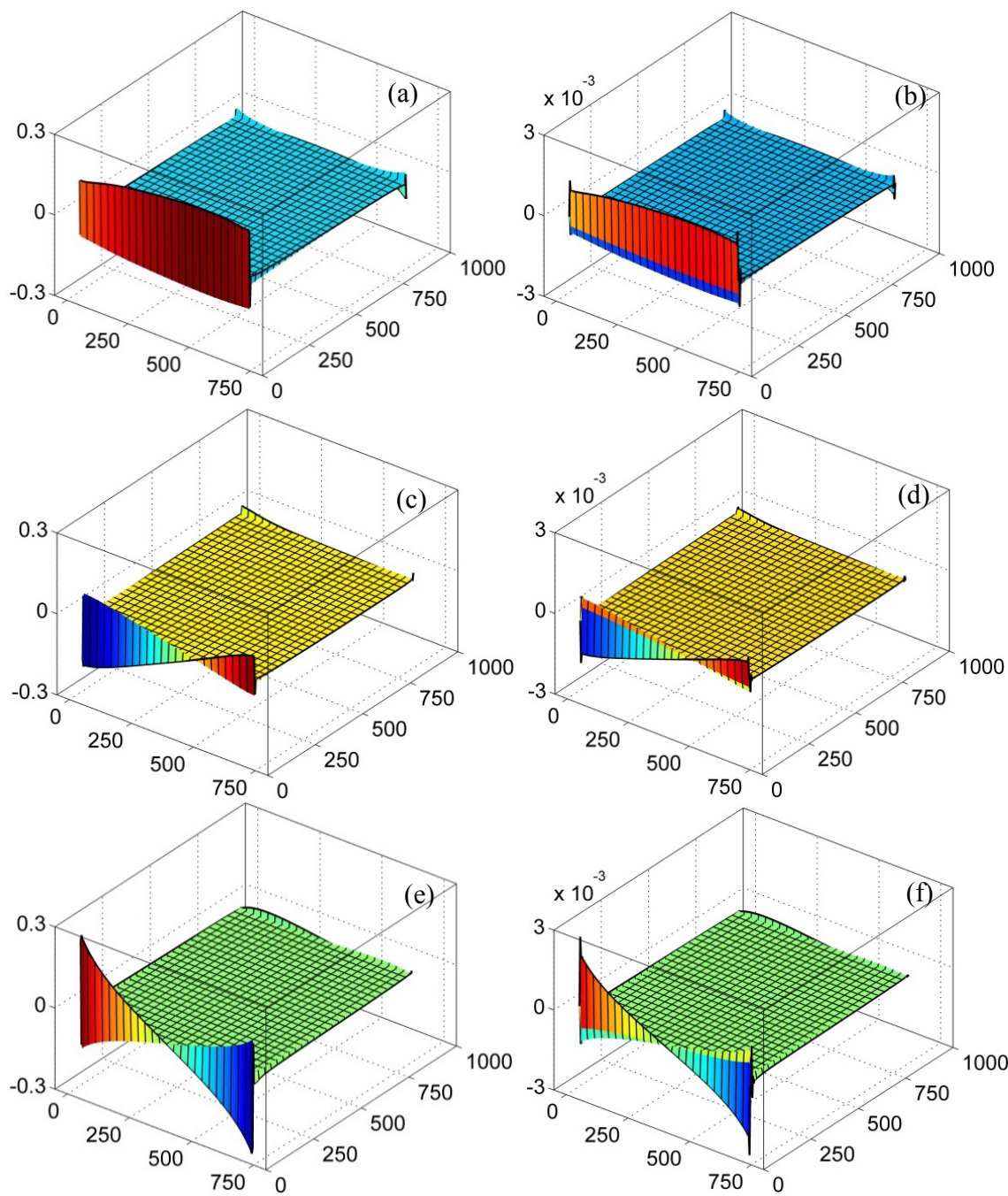

Figure 15. Modal out-of-plane normal stresses at the interfaces of the adhesive layer: (a) first mode, adhesive-wall interface; (b) first mode, adhesive-FRP interface; (c) second mode, adhesive-wall interface; (d) second mode, adhesive-FRP interface; (e) third mode, adhesive-wall interface; (f) third mode, adhesive-FRP interface. 
show the stresses at the adhesive-FRP interface. In all cases, the modes are normalized to have the same level of strain energy.

Figure 7 indicates that for the same level of energy input, the largest displacements are observed in the out-of-plane (1st) and in the twisting (2nd) modes. In both cases, these displacements are "out-of-plane" by nature and they are about 4 orders of magnitude larger than the in-plane displacements attributed to the in-plane mode (Figures 7c,f). On the other hand, Figure 15 reveals that the largest peeling stresses are observed in the in-plane (3rd) mode (Figure 15e). This means that although the in-plane modal displacements are significantly smaller than the ones associated with the out-of-plane modes (per the same energy input), the in-plane vibration is associated with significant interfacial stresses. These stresses may trigger accumulation of interfacial damage or even debonding failures. Figure 15 also reveals that in all three modes, the adhesive-wall interface (Figures 15a,c,e) is subjected to a level of stresses that is much higher than the ones observed in the adhesive-FRP interface (Figures 15b,d,f). The negligible levels of peeling stresses detected at the adhesive-FRP interfaces are due to the small thickness of the FRP layer and its negligible bending rigidity. The thin FRP layer cannot resist significant out-of-plane normal tractions and it forces their decay through the depth the adhesive layer. On the other hand, the variation of the shear stresses along the strengthened region (and mainly near its edges) yields prominent out-of-plane normal stresses that evolve at the vulnerable adhesive-AAC interface.

\section{Response to base excitation}

The second phase of the study examines the response of the strengthened panel to base excitation. This phase aims to gain insight into the response of the strengthened wall to a direct dynamic load and to examine the FE model on a more local level and under a more demanding dynamic scenario. The dynamic load is introduced to the structure through a cyclic base excitation. Two cyclic displacement input signals with frequencies of $4 \mathrm{~Hz}$ and $6 \mathrm{~Hz}$ are examined. These frequencies fall below the natural frequencies of the studied strengthened panel, however, due to setup limitations, higher frequencies and especially frequencies that are close to the natural ones are not examined. The time history of the base displacement and acceleration records measured in the experiment are shown in Figure 16. The acceleration signals are also used as input for the FE analysis.

The results of the FE analysis are compared with the experimental ones on two scales. On the global scale, the accelerations detected by the analysis at the top of the wall are compared with the ones measured in the experiment. On the more local scale, the numerical and experimental relative displacements between the top beam ( $x=375 \mathrm{~mm}, y=900 \mathrm{~mm}$ ) and a point located at $x=325 \mathrm{~mm}, y=820 \mathrm{~mm}$ on the face of the wall (see Figure 1) are compared. In addition, the experimentally and the numerically detected principal strains at $x=430 \mathrm{~mm}$ and $y=515 \mathrm{~mm}$ are also compared. This measure is also attributed to the elastic response of the wall to the dynamic load.

The experimental and numerical accelerations of the top beam due to the two input excitations are plotted in Figure 17. Figures 17a,c refer to the $4 \mathrm{~Hz}$ signal and Figures 17b,d refer to the $6 \mathrm{~Hz}$ signal. The solid lines in Figure 17 stand for the FE results and the dotted lines stand for the experimental values. The comparison between the $x$ component of the accelerations (Figures 17a,b) shows that the numerical results are in reasonable agreement with the experimental ones. Some of the discrepancies that are still observed stem from the effect of the vibrating cables on the accelerometers, an aspect that 

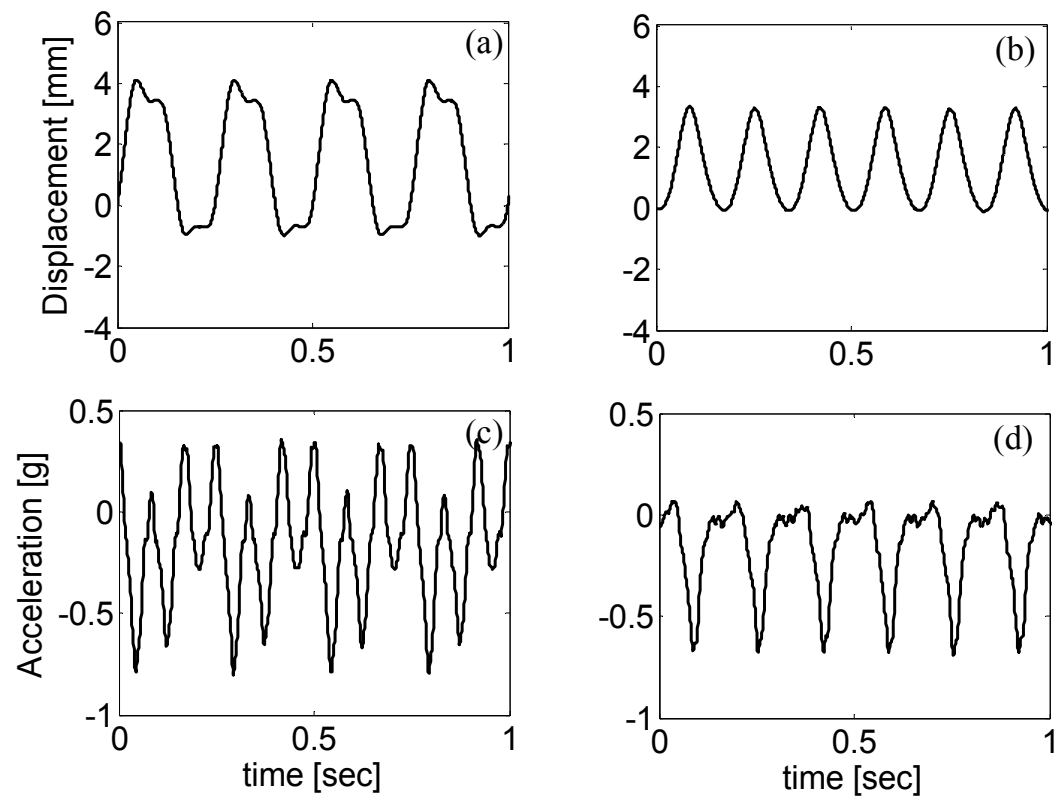

Figure 16. Time history signal of the base excitations: (a) $4 \mathrm{~Hz}$ base motion; (b) $6 \mathrm{~Hz}$ base motion; (c) $4 \mathrm{~Hz}$ base acceleration; (d) $6 \mathrm{~Hz}$ base acceleration.

is not taken into account in the analysis. It is also observed that the high frequency components of the acceleration signals (Figures 17a,b) are more significant in the experimental results (dotted lines) than in the numerical ones (solid lines). This discrepancy is attributed to the way damping is considered in the numerical mode. The Rayleigh damping model (9) and the estimated damping ratios tend to overestimate the impact of damping on the high frequency components. This observation designates the effect of damping as an aspect that requires further research into the dynamics of the FRP strengthened wall and further development of the model.

Figures 17c,d, which refer to the out-of-plane accelerations, reveal that the imperfections in the test setup trigger out-of-plane accelerations in response to the in-plane excitation. These effects are not observed in the "sterile" numerical analysis. The out-of-plane accelerations also trigger out-of-plane inertial forces and therefore a general 3D type of response. For example, in the tested cases, the out-of-plane acceleration goes up to $15 \%$ of the accelerations in the direction of the main excitation. This observation shades on the ability to decompose the analysis of the strengthened wall into a distinct in-plane and outof-plane ones. On the contrary, it indicates that the two cases are coupled. The evolution of out-of-plane accelerations under the in-plane excitation also highlights the role that the strengthening system should take in improving the out-of-plane behavior of the masonry wall and in avoiding its collapse due to out-of-plane dynamic loads (see, for example, [Hamed and Rabinovitch 2008; Rabinovitch and Madah 2012a; 2012b] for dynamic out-of-plane strengthening, testing, and analysis).

The relative in-plane displacement between the top steel beam and the wall, and the relative in-plane displacements between the connection points processed by the FE model are plotted in Figure 18. The experimental curves are marked with dots and the FE results are marked with solid lines. The comparison between the two reveals a good agreement. The agreement is both in terms of the time history pattern 

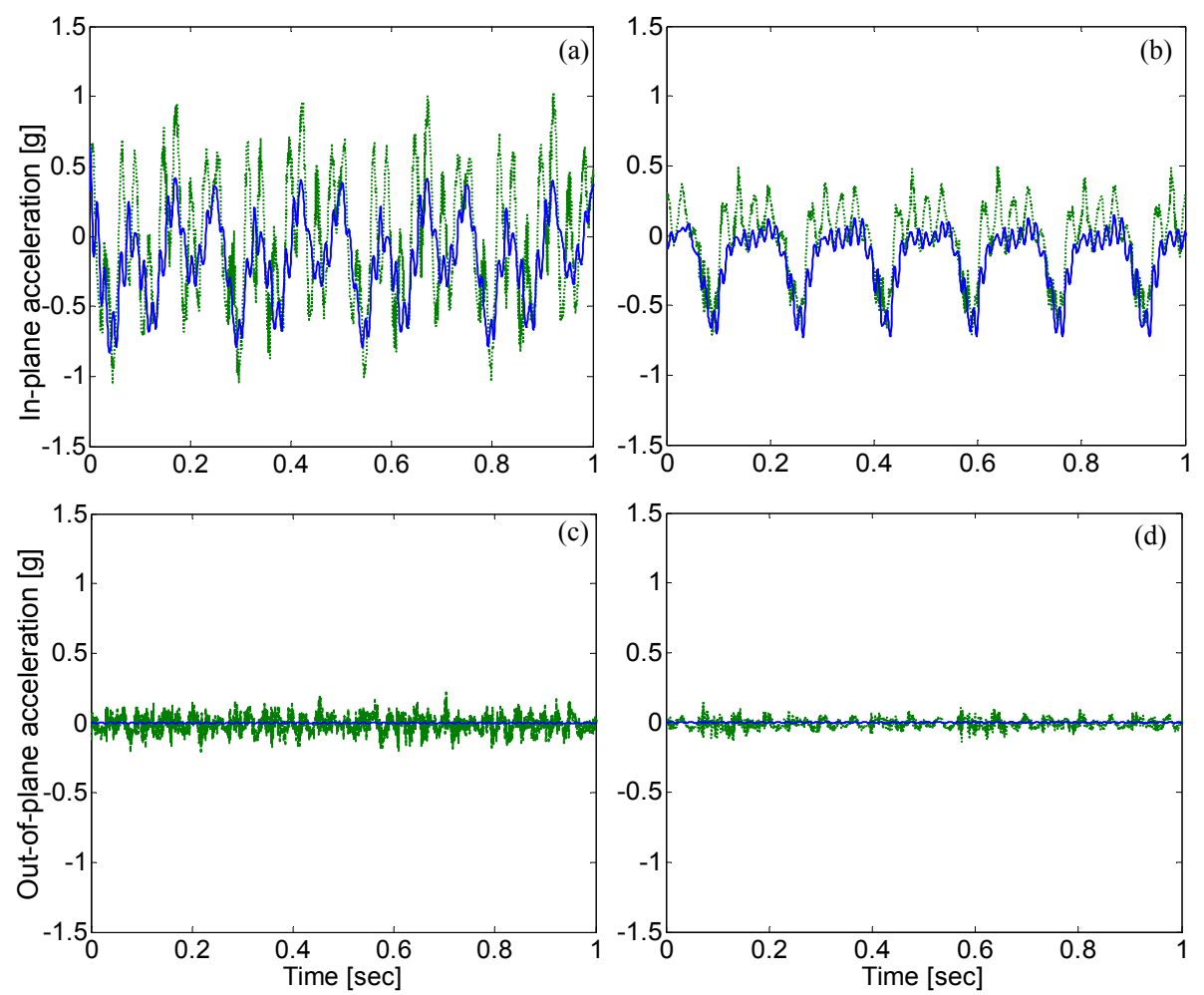

Figure 17. Accelerations of the top beam: (a) in-plane acceleration, $4 \mathrm{~Hz}$ signal; (b) in-plane acceleration, $6 \mathrm{~Hz}$ signal; (c) out-of-plane acceleration, $4 \mathrm{~Hz}$ signal; (d) out-ofplane acceleration $6 \mathrm{~Hz}$ signal. Legend: FEA $; \cdots$. experimental.

and in terms of amplitude and it is observed under both excitations. Opposed to the aspects studied in the previous sections, which are all linked to the global behavior of the tested wall, this relative displacement directly reflects the elastic response of the FRP patched wall to the dynamic load. The agreement between the numerical and the experimental results points at the ability of the FE model to capture and quantify the time dependent elastic response of the strengthened wall.

Another aspect of the localized elastic response of the dynamic load is the evolution of strains in the bonded layers. The strains on the north FRP patch are compared with the dynamic FE results in Figure 19. This comparison is limited to the $6 \mathrm{~Hz}$ signal. For clarity, the measured and the calculated strains are converted into principal ones. The experimental and numerical results reveal that although the excitation with frequencies notably lower than the relevant natural frequency yields a significant rigid body component, it is also involved with an elastic component. The comparison of this dynamic strain signal, which is sufficiently high to be detected by the sensors, with the numerical results reveals good agreement of patterns and magnitudes. The correlation between the numerically determined strains and the experimentally detected ones and the correlation in terms of elastic displacements (Figure 18) demonstrates the ability of the model to detect the dynamic elastic deformation fields.

The magnitude of the deformation component in the dynamic displacement field is amplified when it is tested with the trolley and its added mass. The input acceleration signal and the in-plane acceleration 

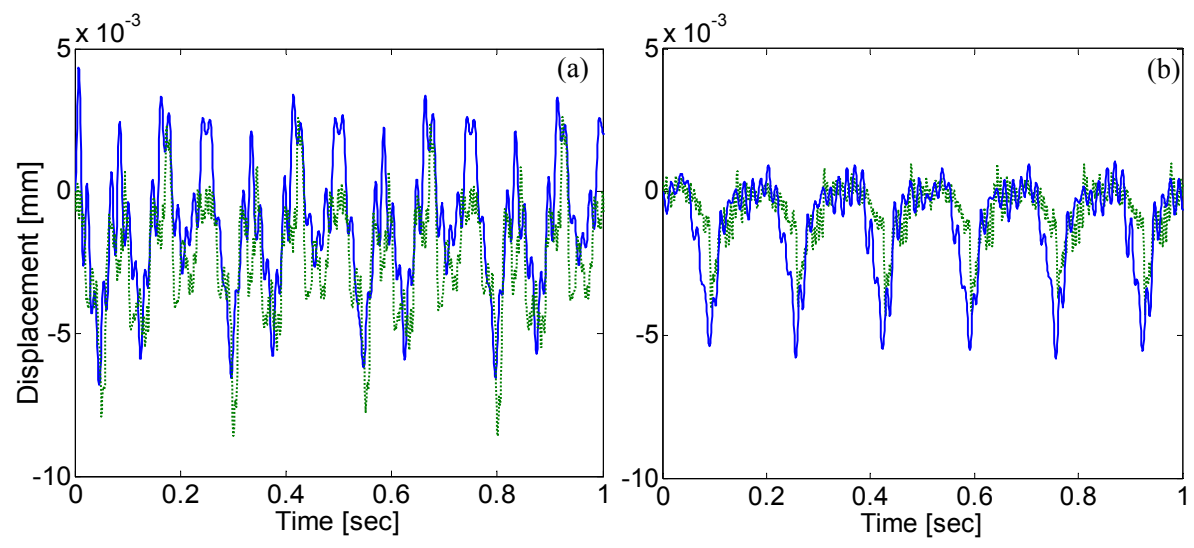

Figure 18. Relative displacement between top steel beam and the FRP patched panel measured by LVDT1: (a) $4 \mathrm{~Hz}$ signal; (b) $6 \mathrm{~Hz}$ signal load. Legend: —— FEA; $\ldots \ldots$. experimental.
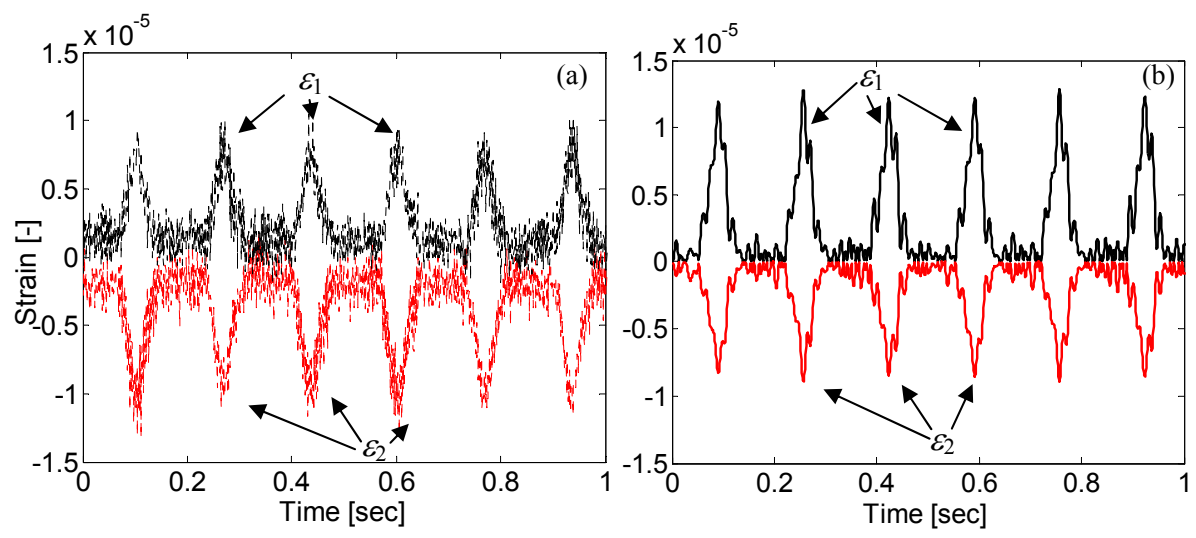

Figure 19. Measured and calculated principal strains at $x=430 \mathrm{~mm}, y=515 \mathrm{~mm}$ versus time: (a) experimental results; (b) numerical results.

measured at the top of the wall when tested with added lateral mass of $580 \mathrm{~kg}$ appear in Figure 20a. Due to the supplemental lateral mass, the input acceleration signal is amplified and the accelerations at the top of the wall are about twice as large as the input signal at its base. The elastic deformation field reflected by the diagonal strains measured at $x=430 \mathrm{~mm}, y=515 \mathrm{~mm}$ and presented in Figure 20b is also more prominent. The levels of strain measured under this dynamic loading condition are about 5 times larger than the ones measured without the added mass. Yet, from a quantitative point of view, the measured strains are still within the capacity limits of the strengthening system and damage to the wall, to the strengthening system, or to the interfaces between them was not observed.

The validation of the FE model and the evolution of an elastodynamic deformation field allow to explore more aspects of the dynamic response of FRP patched wall and to examine ones that cannot be directly detected in the experiment. From a practical point of view, it is interesting to examine the dynamic response of the FRP system and the bond layer. For brevity, this examination focuses on the 

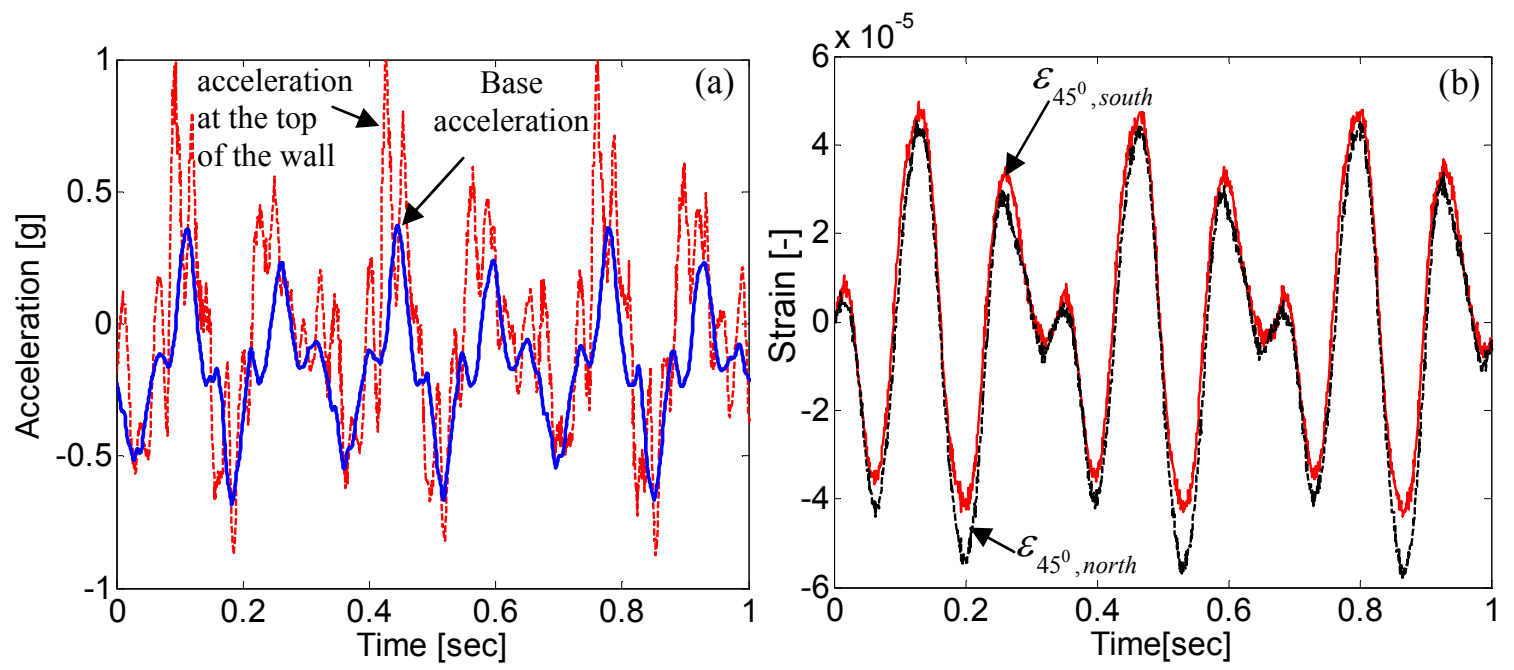

Figure 20. Response to a $6 \mathrm{~Hz}$ base excitation with added mass of $580 \mathrm{~kg}$ : (a) accelerations; (b) diagonal strains on the FRP layer. Legend: —— Base acceleration; - - - in-plane acceleration at the top of the wall; - diagonal strain at $x=430 \mathrm{~mm}, y=515 \mathrm{~mm}$ on the north face; - - diagonal strain at $x=430 \mathrm{~mm}, y=515 \mathrm{~mm}$ on the south face.

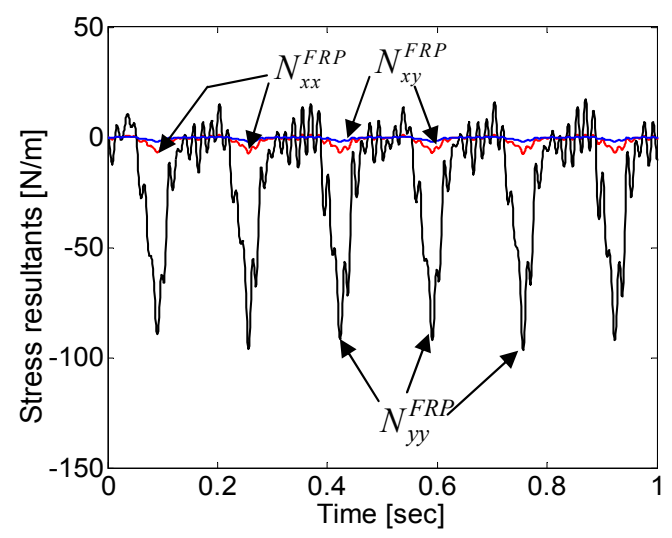

Figure 21. Stress resultants in the south FRP layer due to $6 \mathrm{~Hz}$ excitation versus time.

$6 \mathrm{~Hz}$ cyclic excitation without the added mass. The time history response of the axial and shear resultants in the south FRP layer at $x=125 \mathrm{~mm}$ and $y=125 \mathrm{~mm}$ is studied in Figure 21. The curves indicate that the stress resultant $N_{y y}$ is dominant and it attains values that are much higher than the stress resultants in the $x$ direction and shear resultants. It is also observed that at the examined point, the dominant $N_{y y}$ values are negative and reflect compression. Although the magnitudes are rather small (compared, for example, with the tensile strength of the FRP), the cyclic compression of the thin FRP layer may lead to a geometrical instability (buckling) of the patch. Such potential buckling is an inherent aspect of the response of the FRP strengthened wall to dynamic in-plane loads and it should be taken into account in the design of such systems. 


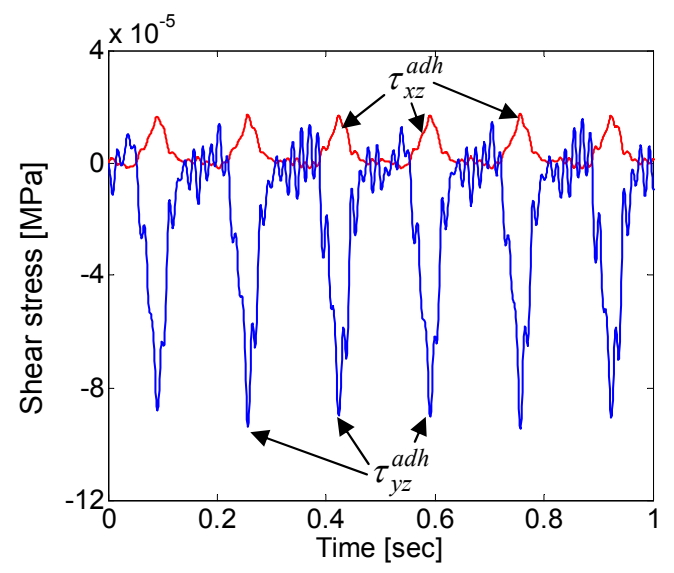

Figure 22. Shear stresses in the south bond layer due to $6 \mathrm{~Hz}$ excitation versus time.

The variation of the interfacial shear stresses at $x=125 \mathrm{~mm}$ and $y=125 \mathrm{~mm}$ in time appears in Figure 22 and reveals that the shear stresses in the $y$ direction $\tau_{y z}$ are higher than $\tau_{x z}$. In addition, they are more affected by the higher frequencies. The pattern of the shear stresses $\tau_{y z}$ corresponds to the one of the axial stress resultants in the $y$ direction and the higher frequency component corresponds to the $67 \mathrm{~Hz}$ of the in-plane mode. This observation indicates that this unique mode is not solely governed by in-plane shear but also by a rocking response driven by the axial stresses in the $y$ direction (Figure 22) and the accompanying shear stresses in the adhesive layer (Figure 21).

The out-of-plane normal stresses at the interfaces of the adhesive layer at $t=0.259 \mathrm{sec}$ are studied in Figure 23. As discussed in the previous section, the interfacial stresses at the adhesive-AAC interface in Figure 23a are much higher than those in the adhesive-FRP interface (Figure 23b). As a result, the brittle adhesive-AAC interface is more susceptible to debonding. The interfacial out-of-plane stresses points at localized effects near the fixed edge of the AAC panel. At this point in time, the distribution of the stresses changes from positive (peeling) stresses to negative stresses along the $x$ axis. Quantitatively, it is observed that the examined excitation, which involve accelerations that go up to about $0.6 \mathrm{~g}$ but central
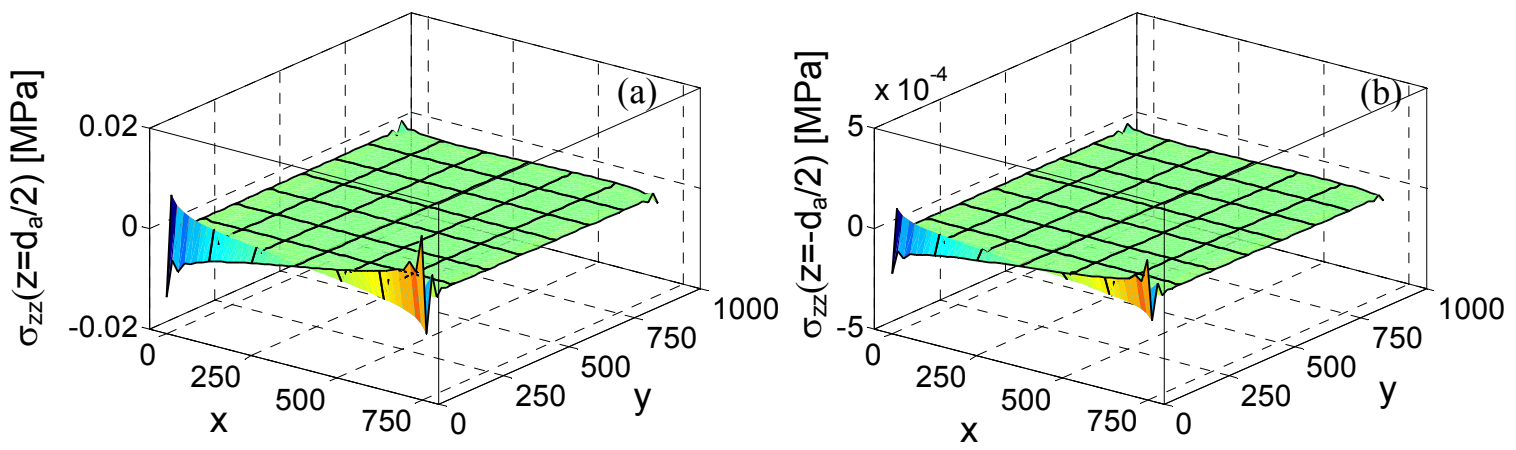

Figure 23. Interfacial out-of-plane normal stresses due to $6 \mathrm{~Hz}$ signal at $t=0.259 \mathrm{sec}$ : (a) adhesive-wall interface; (b) adhesive-FRP interface. (Note the different scales.) 
frequencies that are below the natural frequencies of the wall and relatively small elastic deformations, yields relatively low levels of interfacial stresses. Correspondingly, and in spite of the low tensile strength of the AAC interface, delaminations of the FRP system were not observed in the experiment.

\section{Summary and conclusions}

Dynamic strengthening of masonry structures using externally bonded fiber reinforced plastics is an attractive structural application with a significant potential in the field of dynamic upgrade of structures. In this paper, the 3D dynamic behavior of FRP strengthened AAC masonry panels has been experimentally and numerically studied. The FRP strengthened AAC panel has been dynamically tested under impulsive load that yields a free vibration response and under dynamic base excitations. The natural frequencies of the strengthened panel have been studied and compared with numerical results obtained using a specially tailored FE model. This model combines high-order multilayered 2D elements that are specially tailored for the patched wall with conventional bar, beam and shell elements that model all other components of the test setup. The correlation between the numerical model and the experimental natural frequencies and vibration modes has supported the validity of the FE model. It has also allowed to expand the free vibration analysis and to look into more localized effects such as the modal distribution of interfacial stresses. Strain energy based normalization has allowed quantitatively comparing between the in-plane and the out-of-plane modes, characterizing their impact on the interfacial stresses, and revealing the significant role that the in-plane dynamic response plays in the evolution of such interfacial stresses. In the second phase of the study, the FRP strengthened AAC panel has been subjected to cyclic base excitations. Also here, the dynamic experimental results have been compared with numerical ones and the numerical model has been used for a more localized analysis of the strengthened AAC panel. In this case, the dynamic analysis has focused on the response of the strengthening system.

From the analytical point of view, the comparison between the experimental results and the numerical ones in term of natural frequencies, vibration modes, and dynamic response to base excitation supports the validity of the FE model. The correlation in terms of the free vibration response demonstrates the ability of the model to quantify the global dynamic behavior of the FRP patched AAC masonry wall. The agreement between the numerical and experimental responses to base excitation, and mainly the local aspects that have been examined, demonstrate its ability to quantify some of the localized aspects of the behavior of the wall. The numerical and comparative studies also highlight the strength of the FE model in terms of integrating the specially tailored FE for the FRP patched wall into a broader and more general FE based analysis framework.

From the practical point of view, the experimental and numerical study has highlighted and quantified a range of physical phenomena that characterize the FRP strengthened panel. Among them, the coupling of the in-plane and the out-of-plane responses to the dynamic excitation, the coupling of shear and rocking effects in the in-plane response, and the modes in which the dynamic structural response effectively activates the strengthening system are listed. It has also been observed that all modes and all aspects of the response to base excitation trigger interfacial effects and particularly out-of-plane normal stresses at the adhesive-wall interface. Due to the low bending stiffness of the FRP sheet, these stresses tend to concentrate at the vulnerable adhesive-AAC interface and to decay through the depth of the adhesive layer. 
The experimental observations, the numerical study, and the validation of the numerical model through comparison with experimental benchmarks, throw some light on the dynamic behavior of the FRP strengthened AAC masonry wall. The characterization of some of the local scale results also gains some insight into the dynamic response of the wall. These contributions take another step towards the application of this method for the dynamic strengthening of masonry walls.

\section{Acknowledgement}

This research was supported by The Israel Science Foundation (Grant No. 772/06).

\section{References}

[Al-Chaar and Hasan 2002] G. K. Al-Chaar and H. A. Hasan, "Dynamic response and seismic testing of CMU walls rehabilitation with composite material applied to only one side", Proc. Inst. Civ. Eng. 152:2 (2002), 135-146.

[Almusallam and Al-Salloum 2007] T. H. Almusallam and Y. A. Al-Salloum, "Behavior of FRP strengthened infill walls under in-plane seismic loading", J. Compos. Constr. (ASCE) 11:3 (2007), 308-318.

[Altin et al. 2008] S. Altin, O. Anil, M. E. Kara, and M. Kaya, "An experimental study on strengthening of masonry infilled RC frames using diagonal CFRP strips", Compos. B Eng. 39:4 (2008), 680-693.

[Chopra 2001] A. K. Chopra, Dynamic of structures, 2nd ed., Prentice Hall, New Jersey, NJ, 2001.

[Ehsani et al. 1997] M. R. Ehsani, H. Saadatmanesh, and A. Al-Saidy, "Shear behavior of URM retrofitted with FRP overlays", J. Compos. Constr. (ASCE) 1:1 (1997), 17-25.

[ElGawady et al. 2002] M. A. ElGawady, P. Lestuzzi, and M. Badoux, "Dynamic in-plane behavior of URM wall upgraded with composites", in 3rd International Conference on Composites in Infrastructure, ICCI '02 (San Francisco, 2002), Omnipress/University of Arizona, Tucson, AZ, 2002. CD-ROM.

[ElGawady et al. 2003] M. A. ElGawady, P. Lestuzzi, and M. Badoux, "In-plane lateral behavior of URM walls upgraded with composites", in Response of structures to extreme loading, XL-2003 (Toronto, ON, 2003), edited by A. Ghobarah and P. L. Gould, Elsevier, Boston, 2003. CD-ROM.

[ElGawady et al. 2005] M. A. ElGawady, P. Lestuzzi, and M. Badoux, "In-plane seismic response of URM walls upgraded with FRP", J. Compos. Constr. (ASCE) 9:6 (2005), 524-535.

[Elmalich and Rabinovitch 2012a] D. Elmalich and O. Rabinovitch, "Dynamic analysis of walls strengthened with composite materials", Compos. Struct. 94:7 (2012), 2157-2173.

[Elmalich and Rabinovitch 2012b] D. Elmalich and O. Rabinovitch, "A high-order finite element for dynamic analysis of soft-core sandwich plates", J. Sandw. Struct. Mater. 14:5 (2012), 525-555.

[Elmalich and Rabinovitch 2012c] D. Elmalich and O. Rabinovitch, "Localized effects in walls strengthened with externally bonded composite materials", J. Eng. Mech. (ASCE) 138:9 (2012), 1112-1126.

[Foster et al. 2005] P. B. Foster, J. Gergely, D. T. Young, W. M. McGinley, and A. Corzo, "FRP repair methods for unreinforced masonry buildings subjected to cyclic loading", pp. 289-306 in 7th International Symposium on Fiber-Reinforced (FRP) Polymer Reinforcement for Concrete Structures (Kansas City, MO, 2005), edited by C. K. Shield et al., ACI Special Publication 230, American Concrete Institute, Farmington, MI, 2005.

[Guyan 1965] R. J. Guyan, "Reduction of stiffness and mass matrices", AIAA J. 3:2 (1965), 380.

[Hamed and Rabinovitch 2008] E. Hamed and O. Rabinovitch, "Masonry walls strengthened with composite materials: dynamic out-of-plane behavior", Eur. J. Mech. A Solids 27:6 (2008), 1037-1059.

[Hamed and Rabinovitch 2010] E. Hamed and O. Rabinovitch, "Lateral out-of-plane strengthening of masonry walls with composite materials", J. Compos. Constr. (ASCE) 14:4 (2010), 376-387.

[Hamid et al. 2005] A. A. Hamid, W. W. El-Dakhakhni, Z. H. R. Hakam, and M. Elgaaly, "Behavior of composite unreinforced masonry-fiber reinforced polymer wall assemblages under in-plane loading”, J. Compos. Constr. (ASCE) 9:1 (2005), 73-83. 
[Haroun and Ghoneam 1997] M. A. Haroun and E. H. Ghoneam, "Seismic performance testing of masonry-infilled frames retrofitted by fiber composite", pp. 1650-1656 in Proceedings of the 15th International Modal Analysis Conference, IMAC XV (Orlando, FL, 1997), edited by A. L. Wicks, SPIE 3089, Society for Experimental Mechanics, Bethel, CT, 1997.

[Memari et al. 2010] A. M. Memari, A. Lepage, and J. Setthachayanon, "An experimental study of autoclaved aerated concrete lintels strengthened with externally bonded glass FRP”, J. Reinf. Plast. Compos. 29:22 (2010), 3322-3337.

[Narayanan and Ramamurthy 2000] N. Narayanan and K. Ramamurthy, "Structure and properties of aerated concrete: a review", Cem. Concr. Compos. 22:5 (2000), 321-329.

[Rabinovitch and Madah 2012a] O. Rabinovitch and H. Madah, "Dynamics of FRP strengthened unidirectional masonry walls, I: A multi-layered finite element”, J. Mech. Mater. Struct. 7:1 (2012), 1-28.

[Rabinovitch and Madah 2012b] O. Rabinovitch and H. Madah, "Dynamics of FRP strengthened unidirectional masonry walls, II: Experiments and comparison", J. Mech. Mater. Struct. 7:1 (2012), 29-44.

[Saatcioglu et al. 2005] M. Saatcioglu, F. Serrato, and S. Foo, "Seismic performance of masonry infill walls retrofitted with CFRP sheets", pp. 341-354 in 7th International Symposium on Fiber-Reinforced (FRP) Polymer Reinforcement for Concrete Structures (Kansas City, MO, 2005), edited by C. K. Shield et al., ACI Special Publication 230, American Concrete Institute, Farmington, MI, 2005.

[Serrano-Perez et al. 2007] J. C. Serrano-Perez, U. K. Vaidya, and N. Uddin, "Low velocity impact response of autoclaved aerated concrete/CFRP sandwich plates", Compos. Struct. 80:4 (2007), 621-630.

[Stratford et al. 2004] T. Stratford, G. Pascale, O. Manfroni, and B. Bonfiglioli, "Shear strengthening masonry panels with sheet glass-fiber reinforced polymer", J. Compos. Constr. (ASCE) 8:5 (2004), 434-443.

[Suriya Prakash and Alagusundaramoorthy 2008] S. Suriya Prakash and P. Alagusundaramoorthy, "Load resistance of masonry wallettes and shear triplets retrofitted with GFRP composites", Cem. Concr. Compos. 30:8 (2008), 745-761.

[Turek et al. 2007] M. Turek, C. E. Ventura, and S. Kuan, "In-plane shake-table testing of GFRP-strengthened concrete masonry walls", Earthq. Spectra 23:1 (2007), 223-237.

[Uddin et al. 2006] N. Uddin, F. H. Fouad, U. K. Vaidya, A. K. Khotpal, and J. C. Serrano-Perez, "Structural characterization of hybrid fiber reinforced polymer (FRP)-autoclave aerated concrete (AAC) panels", J. Reinf. Plast. Compos. 25:9 (2006), 981-999.

[Uddin et al. 2007] N. Uddin, F. H. Fouad, U. K. Vaidya, A. K. Khotpal, and J. C. Serrano-Perez, "Structural behavior of fiber-reinforced polymer-autoclaved aerated concrete panels", ACI Struct. J. 104:6 (2007), 722-730.

[Valluzzi et al. 2002] M. R. Valluzzi, D. Tinazzi, and C. Modena, "Shear behavior of masonry panels strengthened by FRP laminates", Constr. Build. Mater. 16:7 (2002), 409-416.

[Zienkiewitch 1977] O. C. Zienkiewitch, The finite element method, McGraw-Hill, London, 1977.

Received 6 Feb 2012. Revised 24 Jun 2012. Accepted 20 Jul 2012.

DVIR Elmalich: dvir@tx.technion.ac.il

Faculty of Civil and Environmental Engineering, Technion - Israel Institute of Technology, Technion City, 32000 Haifa, Israel

ODED RABINOVITCH: croded@tx.technion.ac.il

Faculty of Civil and Environmental Engineering, Technion - Israel Institute of Technology, Technion City, 32000 Haifa, Israel 


\title{
JOURNAL OF MECHANICS OF MATERIALS AND STRUCTURES
}

\author{
jomms.net
}

\author{
Founded by Charles R. Steele and Marie-Louise Steele \\ EDITORS \\ Charles R. STEele \\ DAVIDE BIGONI \\ Stanford University, USA \\ University of Trento, Italy \\ IWONA JASIUK University of Illinois at Urbana-Champaign, USA \\ YASUHIDE SHINDO Tohoku University, Japan
}

\section{EDITORIAL BOARD}

H. D. Bui École Polytechnique, France

J. P. CARTER University of Sydney, Australia

R. M. CHRISTENSEN Stanford University, USA

G. M. L. GLadWELL University of Waterloo, Canada

D. H. Hodges Georgia Institute of Technology, USA

J. Hutchinson Harvard University, USA

C. HwU National Cheng Kung University, Taiwan

B. L. KARIHALOO University of Wales, UK

Y. Y. KIM Seoul National University, Republic of Korea

Z. Mroz Academy of Science, Poland

D. PAmplona Universidade Católica do Rio de Janeiro, Brazil

M. B. RUBIN Technion, Haifa, Israel

A. N. SHUPIKOV Ukrainian Academy of Sciences, Ukraine

T. TARNAI University Budapest, Hungary

F. Y. M. WAN University of California, Irvine, USA

P. WRIGGERS Universität Hannover, Germany

W. YANG Tsinghua University, China

F. ZIEGLER Technische Universität Wien, Austria

PRODUCTION production@msp.org

SILVIO LEVY Scientific Editor

See http://jomms.net for submission guidelines.

JoMMS (ISSN 1559-3959) is published in 10 issues a year. The subscription price for 2012 is US $\$ 555 /$ year for the electronic version, and \$735/year (+\$60 shipping outside the US) for print and electronic. Subscriptions, requests for back issues, and changes of address should be sent to Mathematical Sciences Publishers, Department of Mathematics, University of California, Berkeley, CA 94720-3840.

JoMMS peer-review and production is managed by EditFLow ${ }^{\circledR}$ from Mathematical Sciences Publishers.

\author{
mathematical sciences publishers \\ http://msp.org/ \\ A NON-PROFIT CORPORATION \\ Typeset in $\mathrm{IAT}_{\mathrm{E}} \mathrm{X}$ \\ Copyright $@ 2012$ by Mathematical Sciences Publishers
}




\section{Journal of Mechanics of Materials and Structures}

\section{Volume 7, No. $7 \quad$ September 2012}

Molecular dynamics-based continuum models for the linear elasticity of nanofilms and nanowires with anisotropic surface effects

Wonbae Kim, Seung Yun Rhee and Máenghyo Cho

Characterization of human skin through skin expansion

Djenane C. Pamplona and Claudio R. Carvalho 641

In-plane dynamic excitation of AAC masonry walls patched with FRP: dynamic testing and analysis

DVIR ELMALICH and ODED RABINOVITCH

Hygrothermal analysis of exponentially graded rectangular plates

ASHRAF M. ZENKOUR 687

Green's function for symmetric loading of an elastic sphere with application to contact problems ALEXeY S. TITOVICH and ANDREW N. NORRIS 701

Multi-hit armour characterisation of metal-composite bi-layers

K. Karthikeyan, B. P. Russell, V. S. Deshpande and N. A. Fleck 